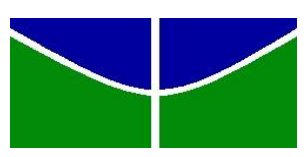

UNIVERSIDADE DE BRASÍLA

FACULDADE DE AGRONOMIA E MEDICINA VETERINÁRIA

USO DE EXTRATO DE GOIABA (Psidium guajava L.) NA PREVENÇÃO DA OXIDAÇÃO DA CARNE DE FRANGO

\author{
SAMARA AQUINO AMADOR
}

DISSERTAÇÃO DE MESTRADO EM CIÊNCIAS ANIMAIS

BRASÍLIA/DF

NOVEMBRO DE 2015 


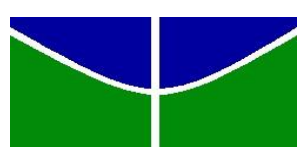

UNIVERSIDADE DE BRASÍLA

FACULDADE DE AGRONOMIA E MEDICINA VETERINÁRIA

USO DE EXTRATO DE GOIABA (Psidium guajava L.) NA PREVENÇÃO DA OXIDAÇÃO DA CARNE DE FRANGO

SAMARA AQUINO AMADOR

ORIENTADOR: ALINE M. C. RACANICCI

DISSERTAÇÃO DE MESTRADO EM CIÊNCIAS ANIMAIS

PUBLICAÇÃO: 142/2015

BRASÍLIA/DF

NOVEMBRO DE 2015 
UNIVERSIDADE DE BRASÍLA FACULDADE DE AGRONOMIA E MEDICINA VETERINÁRIA

USO DE EXTRATO DE GOIABA (Psidium guajava L.) NA PREVENÇÃO DA OXIDAÇÃO DA CARNE DE FRANGO

SAMARA AQUINO AMADOR

DISSERTAÇÃO DE MESTRADO SUBMETIDA AO PROGRAMA DE PÓS-GRADUAÇÃO EM CIÊNCIAS ANIMAIS, COMO PARTE DOS REQUISITOS NECESSÁRIOS À OBTENÇÃO DO GRAU DE MESTRE EM CIÊNCIAS ANIMAIS.

APROVADA POR:

ALINE M. CALIL RACANICCI, Doutora (Universidade de Brasília) (ORIENTADORA)

FRANCISCO ERNESTO MORENO BERNAL, Doutor (Universidade de Brasília)

CANDICE B. G. S. TANURE, Doutora (Universidade de Brasília)

BRASÍLIA/DF, 27 DE NOVEMBRO DE 2015 


\section{ÍNDICE}

\begin{tabular}{|c|c|}
\hline RESUMO & vii \\
\hline ABSTRACT & ix \\
\hline ÍNDICE DE FIGURAS E TABELAS & $\mathrm{x}$ \\
\hline ÍNDICE DE GRÁFICOS & $\mathrm{xi}$ \\
\hline LISTA DE ABREVIAÇÕES & xii \\
\hline $\begin{array}{l}\text { CAPÍTULO } 1 \text { - Uso de extrato de goiaba (Psidium guajava l.) na prevenção da } \\
\text { oxidação da carne de frango. }\end{array}$ & 1 \\
\hline 1. INTRODUÇÃO & 2 \\
\hline 1.1 Problemática e relevância & 3 \\
\hline 1.2 Objetivos & 3 \\
\hline 2. REVISÃO DE LITERATURA & 4 \\
\hline 2.1 Oxidação lipídica da carne de frango & 4 \\
\hline 2.2 Antioxidantes & 6 \\
\hline 2.3 Antioxidantes sintéticos & 8 \\
\hline 2.4 Extratos Vegetais como alternativa natural & 9 \\
\hline 2.5 Compostos fenólicos em plantas & 10 \\
\hline 2.6 Extrato de goiaba (Psidium guajava L.) & 13 \\
\hline $\begin{array}{l}\text { CAPÍTULO } 2 \text { - Uso de extrato de goiaba (Psidium guajava l.) na prevenção da } \\
\text { oxidação da carne de peito frango. }\end{array}$ & 15 \\
\hline RESUMO & 16 \\
\hline ABSTRACT & 17 \\
\hline 1.INTRODUÇÃO & 18 \\
\hline 2.MATERIAL E MÉTODOS & 20 \\
\hline 2.1 Caracterização do extrato de goiaba & 20 \\
\hline 2.2 Fenólicos totais & 20 \\
\hline $2.3 \mathrm{DPPH}$ & 21 \\
\hline 2.4 Preparo e armazenamento das almondegas de peito de frango & 21 \\
\hline 2.5 Análise das amostras resfriadas & 22 \\
\hline 2.6 Análise das amostras congeladas & 22 \\
\hline 2.7 Determinação da oxidação lipídica & 23 \\
\hline 2.8 Análise bromatológica da carne do peito de frango & 23 \\
\hline 2.9 Análise estatística & 24 \\
\hline 3. RESULTADOS E DISCUSSÃO & 25 \\
\hline 3.1 Compostos Fenólicos & 25 \\
\hline 3.2 Atividade antiradical DPPH & 26 \\
\hline 3.3 Composição bromatológica da carne do peito & 28 \\
\hline 3.4 Ensaio de armazenamento refrigerado & 29 \\
\hline 3.5 Ensaio de armazenamento congelado & 33 \\
\hline 4. CONCLUSÃO & 36 \\
\hline 5. REFERÊNDIAS BIBLIOGRÁFICAS & 37 \\
\hline
\end{tabular}




\begin{tabular}{|l|c|}
\hline $\begin{array}{l}\text { CAPÍTULO 3 - Uso de extrato de goiaba (Psidium guajava l.) na prevenção da } \\
\text { oxidação da sobrecoxa de frango. }\end{array}$ & 47 \\
\hline RESUMO & 48 \\
\hline ABSTRACT & 49 \\
\hline 1.INTRODUÇÃO & 50 \\
\hline 2. MATERIAL E MÉTODOS & 52 \\
\hline 2.1 Caracterização do extrato de goiaba & 52 \\
\hline 2.2 Fenólicos totais & 52 \\
\hline 2.3 Atividade antiradical DPPH & 53 \\
\hline 2.4 Preparo e armazenamento das almondegas de sobrecoxa de frango & 53 \\
\hline 2.5 Análise das amostras resfriadas & 54 \\
\hline 2.6 Análise das amostras congeladas & 54 \\
\hline 2.7 Determinação da oxidação lipídica & 55 \\
\hline 2.8 Análise bromatológica da carne da sobrecoxa & 55 \\
\hline 2.9 Análise estatística & 56 \\
\hline 3.RESULTADO E DISCUSSÃO & 57 \\
\hline 3.1 Compostos fenólicos e atividade antiradical DPPH & 57 \\
\hline 3.2 Composição bromatológica da carne da sobrecoxa & 57 \\
\hline 3.3 Ensaio de armazenamento refrigerado & 58 \\
\hline 3.4 Ensaio de armazenamento congelado & 61 \\
\hline 4.CONCLUSÃO & 65 \\
\hline 5. REFERÊNCIA BIBLIOGRÁFICA & 66 \\
\hline CAPÍTULO 4 - CONSIDERAÇÕES FINAIS & 70 \\
\hline
\end{tabular}


RESUMO

\title{
Uso de extrato de goiaba (Psidium guajava l.) na prevenção da oxidação da carne de frango
}

\author{
ALUNO: Samara Aquino Amador ${ }^{1}$ \\ ORIENTADOR: Dra ${ }^{a}$ Aline Mondini Calil Racanicci ${ }^{1}$ \\ 1 - Universidade de Brasília - UNB
}

Foram realizados 2 experimentos avaliando a capacidade antioxidante do extrato de resíduos da goiaba (EG) na preservação da carne de peito e sobrecoxa de frango, em resfriamento e congelamento. O extrato, em pó, utilizado nos experimentos foi composto de casca, semente e poupa de goiaba e foi analisado quanto a quantidade de fenólicos totais e atividade antiradical (DPPH) em diferentes solventes de extração. Para cada experimento, a carne foi adquirida em supermercado local na cidade de Brasília/DF, e foram confeccionadas almondegas précozidas com os tratamentos: CONT: sem adição de antioxidantes; BHT: adição de 0,2\% do antioxidante sintético BHT; 0,5EG: adição de 0,5\% de EG; 1,0EG: adição de 1,0\% de EG; 1,5EG: adição de 1,5\% de EG. As almôndegas de carne pré-cozidas foram armazenadas em um delineamento inteiramente casualizado, refrigeração $\left(4{ }^{\circ} \mathrm{C}\right)$ por 8 dias e em congelamento $\left(-12{ }^{\circ} \mathrm{C}\right)$ por 4 meses, e analisadas periodicamente, em duplicata, quanto a concentração de substâncias reativas ao ácido tiobarbitúrico (TBARS). Os resultados foram analisados utilizando o teste de TUKEY para a comparação das médias, com nível de significância de $5 \%$, e foi feita análise de regressão comparando o tratamento sem extrato com os tratamentos com níveis crescentes de EG, utilizando o PROC Mixed do SAS Enterprise Guide 5.1 (SAS Inc, Cary, NC,USA). O extrato analisado apresentou resultados superiores $(\mathrm{P}<0,05)$ da composição fenólica e de DPPH com extração em água, sendo: 52,22 mg GAE/g, 80,43\% de atividade antioxidante e $81,33 \%$ de porcentagem de inibição. No experimento 1 , realizado com carne de peito de frango, todos os tratamentos conservaram eficientemente $(\mathrm{P}<0,05)$ os lipídios da carne em relação ao CONT, sob resfriamento ou congelamento, superando inclusive o BHT, porém o 1,5EG foi o tratamento mais eficaz $(\mathrm{P}<0,05)$ no controle da oxidação lipídica. Foram encontradas regressões lineares negativas significativas $(\mathrm{P}<0,05)$ e, aplicando-as para predizer o valor ótimo de inclusão do EG para minimizar a produção de TBARS foram encontrados os valores de $1,62 \%$ para refrigeração e $1,81 \%$ para 
congelamento. No experimento 2, que utilizou a sobrecoxa de frango, todos os tratamentos aumentaram $(\mathrm{P}<0,05)$ a estabilidade oxidativa do produto, em comparação com CONT, sendo que $1,5 \mathrm{EG}$ e $1,0 \mathrm{EG}$ foram superiores $(\mathrm{P}<0,05)$ ao $\mathrm{BHT}$. Para o armazenamento congelado, todos os tratamentos reduziram significativamente $(\mathrm{P}<0,05)$ os valores médios de TBARS em relação ao CONT, indicando maior preservação dos lipídios, , porém 1,0EG, 1,5EG e BHT não foram diferentes estatisticamente. No calculo da predição do valor ótimo de EG utilizando as equações de regressão lineares negativas significativas $(\mathrm{P}<0,05)$ encontradas, os valores foram: $1,66 \%$ para o armazenamento resfriado e 1,61\% para o congelado. Em conclusão, o extrato de goiaba pode ser uma alternativa natural eficiente na prevenção da oxidação lipídica em produtos à base de carne de frango.

Palavras-chave: peito, sobrecoxa, antioxidante natural, estabilidade oxidativa, BHT, TBARS 


\title{
ABSTRACT \\ The use of guava (Psidium guajava l.) extract on preventing lipid oxidation in chicken meat
}

\author{
ALUNO: Samara Aquino Amador ${ }^{1}$ \\ ORIENTADOR: Dra ${ }^{a}$ Aline Mondini Calil Racanicci ${ }^{1}$ \\ ${ }^{1}$ - Universidade de Brasília - UNB
}

Two experiments were conducted to evaluate the antioxidant capacity of guava residue extract in preserving pre-cooked chicken breast and thigh meat balls during chilled and frozen storage. The extract was composed of the dried residue containing pulp, seeds and skin of guava was and analyzed for DPPH and total phenolics in different solvents for extraction. For each experiment fresh chicken meat was purchased in local supermarket in Brasilia/DF, and used to prepare pre-cooked meatballs with the following treatments: CONT: without antioxidants; BHT: addition of $0.2 \%$ of the synthetic antioxidant BHT; 0.5EG: addition of $0.5 \%$ of guava extract (EG); 1,0EG: addition of $1.0 \%$ of EG; 1,5EG: addition of $1.5 \%$ of EG. The samples were stored in a complete randomized design in -chilled $\left(4{ }^{\circ} \mathrm{C}\right)$ for 8 days and frozen $\left(-12^{\circ} \mathrm{C}\right)$ storage for 4 months, and analyzed in duplicate periodically for TBARS (Thiobarbituric acid reactive substances). The results were analyzed using the Tukey test with 5\% significance and linear regression analysis between treatments with EG using the Mixed SAS Enterprise Guide 5.1 (SAS Inc, Cary, NC, USA). The EG showed higher $(p<0.05)$ values extracted in water: $52.22 \mathrm{mg} \mathrm{GAE} / \mathrm{g}, 80.43 \%$ of antioxidant activity and $81.33 \%$ of inhibition. In experiment 1 using chicken breast meat balls, all treatments preserved $(\mathrm{p}<0.05)$ lipids from oxidation, when compared to CONT during chilled and frozen storage. TBARS results were lower $(\mathrm{p}<0.05)$ compared to BHT, however, 1.5EG was the most effective treatment. As increased EG addition to meat products, a significant $(\mathrm{p}<0.05)$ reduction in TBARS values was seen and reflected in significant $(\mathrm{p}<0.05)$ negative regression that resulted in $1.62 \%$ and $1.81 \%$ EG for minimal TBARS production during chilled and frozen storage, respectively Experiment 2 showed a positive and significant $(\mathrm{p}<0.05)$ effect of the antioxidants in general on the lipid stability, compared to CONT, however, $1.0 \% \mathrm{EG}$ and $1.5 \% \mathrm{EG}$ reduced $(\mathrm{p}<0.05)$ 
TBARS more than BHT during chilled storage. During frozen storage all treatments were effective ( $\mathrm{p}<0.05$ ) when compared to CONT, but $1.0 \% \mathrm{EG} ; 1.5 \% \mathrm{EG}$ and BHT did not differ. Applying significantly negative linear regression, the addition of $1.7 \%$ and 1.6 of EG should minimize TBARS production during chilled and frozen storage, respectively. In conclusion, EG can be an efficient natural antioxidant to improve lipid stability in chicken meat products.

Keywords: breast meat, thigh meat, natural antioxidant, oxidative stability, BHT, TBARS 


\section{ÍNDICE DE FIGURAS E TABELAS}

\section{CAPÍTULO 1}

FIGURAS

PÁGINA

1.1 Esquema do mecanismo de oxidação ...................................................................... 5

1.2 Mecanismo de ação dos antioxidantes primários ....................................................... 7

1.3: Estrutura Fenólica doa Antioxidantes Sintéticos..................................................... 8

1.4 Estrutura química dos ácidos hidroxibenzóicos (a) e hidroxicinâmicos (b) ................ 11

1.5: Árvore Psidium guajava e seu fruto ........................................................................ 13

\section{TABELA}

1.1: Classe dos compostos fenólicos em plantas 11

\section{CAPÍTULO 2}

\section{TABELA}

2.1-Compostos Fenólicos Totais do extrato de goiaba em água, etanol e acetona. 24

2.2 Médias e desvio da composição bromatológia e tabela TACO 27

2.3- Valores médios de TBARS ( $\mu$ mol MDA/kg de carne) em almôndegas de carne de peito pré-cozidas e armazenadas por até 8 dia 30

2.4 Valores médios de TBARS ( $\mu$ mol MDA/kg de carne) em almôndegas de carne de peito pré-cozidas e armazenadas por até 4 meses 32

\section{CAPÍtULO 3}

\section{TABELA}

3.1 Médias e desvio da composição bromatológia e tabela TACO. 58

3.2 Valores médios de TBARS ( $\mu$ mol MDA/kg de carne) em almôndegas de carne de sobrecoxa pré-cozidas e armazenadas por até 8 dia

3.3 Valores médios de TBARS ( $\mu$ mol MDA/kg de carne) em almôndegas de carne de sobrecoxa pré-cozidas e armazenadas por até 4 meses 


\section{ÍNDICE DE GRÁFICOS}

\section{CAPÍTULO 2}

\section{PÁGINA}

2.1 Porcentagem de inibição para o extrato de goiaba em água, etanol e acetona em comparação com o antioxidante BHT

2.2 Atividade antioxidante para o extrato de goiaba em água, etanol e acetona, em comparação com o antioxidante BHT

2.3 Acúmulo de compostos secundários da oxidação lipídica (TBARS, umol MDA/kg de carne) das almondegas de frango cruas e cozidas

2.4 Valores de TBARS ( $\mu$ mol MDA/kg) das almôndegas pré-cozidas de peito de frango armazenadas sob refrigeração durante 8 dias, contendo diferentes dosagens de extrato de goiaba ou BHT

2.5 Valores de TBARS ( $\mu$ mol MDA/kg ) em almôndegas de peito de frango congelado durante 4 meses com diferentes dosagens de extrato de goiaba e BHT.

\section{CAPÍTULO 3}

3.1 Análise de TBARS das almondegas de frango antes e após o cozimento

3.2 Valores de TBA de sobrecoxa de frango refrigerado durante 8 dias, em diferentes dosagens de extrato de goiaba, BHT

3.3 Valores de TBARS do peito de frango refrigerado durante 4 meses, em diferentes dosagens de extrato de goiaba, BHT. 


\section{LISTA DE ABREVIAÇÕES}

$\begin{array}{ll}\text { ANVISA } & \text { Agência Nacional de Vigilância Sanitária } \\ \text { BHT } & \text { hidroxitolueno butilato } \\ \text { BHA } & \text { Butil-hidroxi-anisol } \\ \text { CONT } & \text { controle negativo } \\ \text { DPPH } & \text { atividade antiradical } \\ \text { EE } & \text { extrato etério } \\ \text { EG } & \text { extrato de goiaba } \\ \text { FDA } & \text { Food and Drug Administration } \\ \text { GAE } & \text { equivalente em ácido gálico } \\ \text { MDA } & \text { malondialdeído } \\ \text { MM } & \text { matéria mineral } \\ \text { PB } & \text { proteína bruta } \\ \text { PG } & \text { propil-galato } \\ \text { TBARS } & \text { substâncias reativas ao ácido Tiobarbitúrico } \\ \text { TBHQ } & \text { terc-butil hidroquinona } \\ \text { UFG } & \text { Universidade Federal do Goiás } \\ \text { UM } & \text { umidade } \\ \text { UNB } & \text { Universidade Federal de Brasília }\end{array}$




\section{CAPÍTULO 1}

USO DE EXTRATO DE GOIABA (Psidium guajava L.) NA PREVENÇÃO DA OXIDAÇÃO DA CARNE DE FRANGO 


\section{INTRODUÇÃO}

Em função do elevado teor de ácidos graxos insaturados na sua composição, a carne de frango é um alimento altamente susceptível à oxidação lipídica, o que pode afetar o sabor, o aroma, a cor e a textura da carne, limitando sua estabilidade e vida útil (Almeida et al., 2013).

A oxidação lipídica é um dos principais fatores que afetam a vida de prateleira e as características sensoriais de produtos cárneos, sendo responsável por grandes perdas econômicas. O nível em que essa oxidação ocorre está diretamente relacionado a vários fatores como a quantidade de ácidos graxos poli-insaturados na carne, a presença de íons metálicos, oxigênio, pigmentos heme, processos mecânicos realizados e a adição de sal durante o processamento (Devatkal, Narsaiah, \& Borah, 2010).

Como forma de diminuir os efeitos da oxidação lipídica, as indústrias utilizam antioxidantes sintéticos tais como o hidroxianisol butilado (BHA), hidroxitolueno butilado (BHT) e o butilhidroquinona terciário (TBHQ) (Valência et al., 2007). Porém, segundo Govaris et al. (2010), com o aumento da preocupação com a segurança dos aditivos químicos nos últimos anos, os consumidores têm exigido a utilização de produtos naturais como conservantes alternativos para alimentos.

Da gama de substâncias antioxidantes conhecidas e que podem aumentar o tempo de prateleira dos produtos, estão os compostos fenólicos, presentes em vegetais e frutos. O interesse pelo uso de substâncias naturais com propriedades antioxidantes é decorrente da sua baixa toxicidade e forte atividade, em comparação aos compostos sintéticos (ROCKENBACH et al., 2007).

O extrato de goiaba (Psidium guajava L.) tem sido considerado um produto de considerável atividade antioxidante devido aos elevados níveis de compostos fenólicos em sua composição, tais como fitoflueno, $\beta$-caroteno, $\beta$-criptoxantina, $\gamma$-caroteno, licopeno, ácido 
ascórbico, rubixantina, criptoflavina, luteína e neocromo (Mercadante et al., 1999). Os elevados níveis de flavonoides presentes no extrato de goiaba conferem ainda um alto poder antibacteriano, podendo ser usado também como controlador de patógenos de origem alimentar e de deterioração (Mahfusul et al.,2007).

\subsection{Problemática e Relevância}

O Brasil é um grande produtor de goiaba e seus produtos, como doces e sucos, por exemplo, sendo a produção brasileira de 345,3 mil toneladas de goiaba em 2012 segundo o IBGE. (2012). Porém, uma grande parte dos resíduos da goiaba compostos por casca, sementes e poupa são desperdiçados nos processos industriais. Esses resíduos são ricos em antioxidantes provenientes dos flavonoides presentes na goiaba, podendo ser aproveitados na indústria animal.

A carne de frango possui um curto tempo de prateleira, já que possui grande quantidades de ácidos graxos insaturados na sua estrutura, o que leva a uma alta velocidade da oxidação dos lipídios, em comparação a carne bovina. A ANVISA (órgão que regulamenta e fiscaliza os alimentos no Brasil) não determina prazos específicos de validade, cabendo a cada fabricante sua determinação, sendo que para carne de frango em refrigeração essa validade é em torno de 5 dias e sob congelamento de 8 meses, de acordo com os prazos estabelecidos pelas indústrias de alimentos. Esse curto período de armazenamento pode causar grandes perdas econômicas, principalmente, em produtos à base de carne como almôndegas, hambúrgueres e embutidos, sendo necessário o uso de produtos antioxidantes para aumentar o prazo de validade desses produtos.

\subsection{Objetivos}

Assim, o objetivo do presente trabalho foi avaliar o poder antioxidante do extrato de goiaba em diferentes dosagens, na preservação da carne do peito e da sobrecoxa de frango processada e armazenada por resfriamento e congelamento, em comparação com o antioxidante sintético. 


\section{REVISÃO DE LITERATURA}

\subsection{Oxidação lipídica da carne de frango}

A oxidação lipídica ocorre através de uma série de reações que se inicia por meio de radicais livres altamente reativos, que se unem com oxigênio ou ácidos graxos gerando mais radicais livres e hidroperóxidos, causando uma reação em cadeia. Esse processo ocorre em três fases, iniciação, propagação e terminação, e é responsável pela rancidez dos produtos alimentícios, podendo ocorrer tanto no armazenamento e processamento quanto no re-aquecimento dos produtos cárneos (Hamilton et al., 1997 \& Araujo et al., 2008).

As fases da oxidação lipídica são:

- Iniciação: formação dos radicais livres do ácido graxo devido à retirada de um hidrogênio do carbono alílico na molécula do ácido graxo, em condições favorecidas por luz e calor.

- $\quad$ Propagação: os radicais livres que são prontamente susceptíveis ao ataque do oxigênio atmosférico são convertidos em outros radicais, formando os produtos primários da oxidação (peróxidos e hidroperóxidos), cuja estrutura depende da natureza dos ácidos graxos presentes. Os radicais livres formados atuam como propagadores da reação, resultando em um processo autocatalítico.

- Terminação: dois radicais combinam-se, com a formação de produtos estáveis (produtos secundários de oxidação) obtidos por cisão e rearranjo dos peróxidos (Toledo et al.,1985; Berger et al., 1995; Silva et al., 1999; Ramalho \& Jorge, 2006). 
$\underline{\text { INICIACC̃̃O }}$

$\underline{\text { PROPAGACỸ̃O }}$

TERMINAÇÃO
$\mathrm{RH} \rightarrow \mathrm{R}^{*}+\mathrm{H}^{*}$

$$
\begin{aligned}
& \mathrm{R}^{*}+\mathrm{O}^{2} \rightarrow \mathrm{ROO} * \\
& \mathrm{ROO}^{*}+\mathrm{RH} \rightarrow \mathrm{ROOH}+\mathrm{R}^{*}
\end{aligned}
$$

$\left.\begin{array}{l}\mathrm{ROO}^{*}+\mathrm{R}^{*} \rightarrow \mathrm{ROOR} \\ \mathrm{ROO}^{*}+\mathrm{ROO}^{*} \rightarrow \mathrm{ROOR}+\mathrm{O}^{2} \\ \mathrm{R}^{*}+\mathrm{R}^{*} \rightarrow \mathrm{RR}\end{array}\right\} \begin{aligned} & \text { produtos } \\ & \text { estáveis }\end{aligned}$

Sendo que: RH (ácido graxo insaturado); R* (radical livre); ROO* (radical peróxido); ROOH (hidroperóxido).

Figura 1.1: Esquema do mecanismo de oxidação adaptado de Ramalho \& Jorge. (2006).

A carne de frango é um alimento com elevado teor de ácidos graxos insaturados e, por isso, altamente suscetível a oxidação lipídica, a formação de óxidos de colesterol e as alterações na composição de ácidos graxos, com consequente formação de compostos voláteis resultantes da oxidação lipídica. Fatores que levam a perda de qualidade e das características nutricionais durante o processamento e o armazenamento da carne de frango (Mariutti \& Bragagnolo, 2009).

As alterações na qualidade da carne devido à oxidação lipídica podem ser percebidas pelas mudanças de cor, de textura, de sabor, de valor nutricional e pela produção de compostos tóxicos. As condições de processamento, como o tratamento térmico, a aplicação de alta pressão, a moagem, a adição de outros ingredientes a formulação do produto, o tipo de embalagem, a exposição à luz e a temperatura de armazenamento, são exemplos de fatores extrínsecos que interferem diretamente no processo de oxidação lipídica da carne de frango (Mariutti \& Bragagnolo,2009).

O método de cocção aplicado na carne altera o teor de lipídios totais encontrados na carne cozida em comparação com a carne crua, aumentando o teor de lipídios cerca de duas a três vezes, devido à perda de água durante o processo. De acordo com Cantor et al. (2008), a composição de ácidos graxos no frango assado ou cozido é menor quando comparados ao frango cru.

Já o período de armazenamento e o tratamento térmico não alteram a composição dos ácidos graxos de produtos processados de carne de frango. Entretanto, segundo Mariutti \& Bragagnolo (2009), a adição de condimentos a carne de frango, além de conferir as 
características organolépticas desejadas, também pode auxiliar na sua preservação, prevenindo ou retardando sua deterioração durante o processamento ou armazenamento.

O desenvolvimento da rancidez oxidativa agrava-se durante o armazenamento da carne de frango mesmo sob congelamento, pois, enquanto as reações deteriorativas (microbiológicas e enzimáticas) podem ser inibidas com o emprego de baixas temperaturas, a oxidação lipídica ocorre normalmente em temperaturas baixas, embora numa velocidade reduzida, além disso, este processo destrói as membranas intracelulares, diminuindo a suculência e o peso da carne (Grau et al., 2000; Gardini, 2001; Gomes et al., 2003).

\subsection{Antioxidantes}

De acordo com o órgão regulador de alimentos e medicamentos dos Estados Unidos da América, FDA (Food and Drug Administration), os antioxidantes são definidos como substâncias utilizadas para preservar e estender o "shelf-life" (tempo de prateleira) de alimentos que contém lipídios oxidáveis, através do retardo da descoloração, rancidez e deterioração decorrentes da oxidação. Segundo Ramalho \& Jorge (2006) do ponto de vista químico, os antioxidantes são compostos aromáticos que possuem pelo menos uma hidroxila e podem derivar de fontes comerciais sintéticas, até compostos isolados naturalmente dos alimentos.

Os antioxidantes retardam o aparecimento de alterações oxidativas e de rancificação nos alimentos, principalmente em relação ao odor e sabor desagradáveis, através de quatro principais mecanismos: doação de hidrogênio; doação de elétrons; adição do lipídio ao anel aromático do antioxidante; formação de um complexo entre lipídio e o anel aromático do antioxidante (Carvalho, 2005).

Além disso, segundo Bailey et al. (1996), os antioxidantes podem ser classificados em primários, sinergistas, removedores de oxigênio, biológicos, agentes quelantes e antioxidantes mistos.

- Primários: compostos fenólicos que agem removendo ou inativando radicais livres formados durante a propagação ou iniciação da reação, doando átomos de hidrogênio a estas moléculas e interrompendo a reação em cadeia. Alguns exemplos são os polifenóis, como BHA, BHT, TBHQ e propil galato (PG), que são sintéticos, e os tocoferóis que são naturais e também se encaixam na classe dos antioxidantes biológicos (Fukumoto \& Mazza, 2000) 
- Sinergistas: substâncias com baixa ou nenhuma atividade antioxidante, que combinados corretamente com antioxidantes primários podem aumentar sua atividade. Alguns antioxidantes primários quando utilizados em conjunto, podem atuar de forma sinérgica (Yeum et al., 2009)

- Removedores de oxigênio: compostos que capturam o oxigênio presente no meio, por meio de reações químicas estáveis tornando-os indisponíveis para atuarem como propagadores da oxidação. Os mais conhecidos são os ácidos ascórbicos, seus isômeros e derivados (Choe \& Min, 2009)

- Biológicos: enzimas que podem remover oxigênio ou compostos altamente reativos de um sistema alimentício, como as catalases, a glucose oxidase e o superóxido desmutase (Iqbal et al., 2002)

- Agentes quelantes: são capazes de complexar íons metálicos, principalmente cobre e ferro, que catalisam a oxidação lipídica. Um par de elétrons não compartilhado na sua estrutura molecular promove a ação de complexação. Os mais comuns são o ácido cítrico e seus sais, fosfatos e sais de ácido etileno diamino tetra acético (EDTA) (Yanishlieva-Maslarova, 2001)

- Antioxidantes mistos: são compostos de animais e plantas que têm sido amplamente estudados como antioxidantes em alimentos. Entre eles estão várias proteínas hidrolisadas, flavonoides e derivados do ácido cinâmico (Bailey,1996).

\footnotetext{
$\mathrm{ROO}^{*}+\mathrm{AH} \rightarrow \mathrm{ROOH}+\mathrm{A}^{*}$$$
\mathrm{R}^{*}+\mathrm{AH} \rightarrow \mathrm{RH}+\mathrm{A}^{*}
$$

Em que: ROO* e R* (radicais livres); $\mathrm{AH}$ (antioxidante com um átomo de hidrogênio); $\mathrm{A}^{*}$ (radical inerente)
}

Figura 1.2: Mecanismo de ação dos antioxidantes primários (adaptado de Ramalho \& Jorge .,2006).

Nem todos os antioxidantes podem ser utilizados em alimentos, assim faz-se necessário selecionar antioxidantes com as seguintes características: eficácia em baixas concentrações $(0,001$ a $0,01 \%)$; compatibilidade com o alimento e facilidade de aplicação sem efeitos indesejáveis na cor, no odor, no sabor e em outras características do alimento; estabilidade nas condições de processamento e armazenamento; ausência de compostos e 
produtos de oxidação tóxicos, mesmo em doses muitos maiores das que normalmente seriam ingeridas no alimento (Bailey, 1996).

No Brasil, o órgão que regulamenta os antioxidantes sintéticos que podem ser utilizados em alimentos e qual a concentração permitida de uso, é a Agencia Nacional de Vigilância Sanitária (ANVISA) por meio da RDC n. 45, de 03 de novembro de 2010, através do Regulamento Técnico sobre aditivos alimentares autorizado segundo as Boas Práticas de Fabricação (BPF).

\subsection{Antioxidantes sintéticos}

$\mathrm{Na}$ indústria de alimentos, a oxidação lipídica é inibida por sequestradores de radicais livres, neste caso, os compostos mais utilizados foram citados anteriormente e são: BHA, BHT, TBHQ e PG. Esses compostos possuem uma estrutura fenólica que permite doação de um próton a um radical livre que irá regenerar a molécula do acilglicerol interrompendo o mecanismo de oxidação por radicais livres (Ramalho \& Jorge, 2006).<smiles>Cc1cc(C)c(O)c(C(C)(C)C)c1</smiles>

BHA<smiles>O=C(OCCCCO)c1cc(O)c(O)c(O)c1</smiles>

PG<smiles>COc1ccc(O)c(C(C)(C)C)c1</smiles>

BHT<smiles>CC(C)(C)c1cc(O)ccc1O</smiles>

TBHO

Figura 1.3: Estrutura Fenólica doa Antioxidantes Sintéticos (adaptado de Ramalho \& Jorge .,2006) 
Além das suas características estruturais, a eficácia dos antioxidantes também depende da concentração utilizada, da temperatura aplicada, da exposição à luz, e do tipo de substratos (Yanishlieva \& Marinova, 2001).

Os antioxidantes BHA e BHT possuem mecanismos de ação semelhantes sendo mais efetivos na supressão da oxidação em gorduras animais do que em óleos vegetais e apresentam pouca estabilidade frente a elevadas temperaturas, mas são particularmente efetivos no controle de oxidação de ácidos graxos de cadeia curta.

No Brasil, os antioxidantes autorizados pela ANVISA para uso em produtos cárneos são o ácido ascórbico, o ascorbato de sódio, o ascorbato de cálcio, o ascorbato de potássio, o ácido eritórbico, o ácido isoascórbico, o eritorbato de sódio, o isoascorbato de sódio, BHA, BHT e o PG.

Estudos toxicológicos têm apontado para a possibilidade destes antioxidantes apresentarem algum efeito tóxico, como por exemplo efeitos negativos na regulação da atividade da proteína quinase (Kosarski el al.,2014), hemorragia massiva nas cavidades pleurais e peritoneais (Takahashi\&Hiraga, 1978) ou extensa proliferação de células no pulmão, com mudanças bioquímicas, atuando como agente promotor no desenvolvimento de carcinomas (Witschi \& Lock, 1978). Isso leva a uma necessidade de pesquisas direcionadas no sentido de encontrar produtos naturais com atividade antioxidante, os quais permitirão substituir os sintéticos ou fazer associações entre eles, com intuito de diminuir sua quantidade nos alimentos.

Devido a essa toxicidade a ANVISA limita o uso dos antioxidantes em $200 \mathrm{mg} / \mathrm{kg}$ para BHA e TBHQ e 100 mg/kg para BHT (ANVISA-LEGIS).

\subsection{Extratos vegetais como alternativa natural}

Devido à possível toxicidade dos antioxidantes sintéticos e à demanda atual por produtos mais saudáveis, o uso de antioxidantes naturais representa uma alternativa na prevenção da oxidação lipídica em carne de frango (Selani, 2010).

De acordo com Traesel et al. (2011), o potencial antioxidante dos extratos vegetais está relacionado à presença de compostos fenólicos, flavonóides e terpenóides em sua estrutura química. Essas substâncias podem interceptar e neutralizar radicais livres, impedindo a propagação do processo oxidativo. Diversos extratos de ervas como alecrim, coentro, sálvia, orégano, tomilho e manjericão têm sido estudados devido à sua capacidade 
antioxidante, que pode ser atribuída ao seu conteúdo de compostos fenólicos (Wettasinghe et al., 1999).

Em frutas, principalmente cítricas, também são encontradas grandes quantidades de compostos fenólicos, sendo que esses compostos são geralmente presentes em maiores quantidades na polpa do que no suco da fruta. Outros vegetais como a pimenta, o brócolis, o repolho, o alho e a cebola também são excelentes fontes de substâncias fenólicas, sendo que existem cerca de cinco mil fenóis conhecidos, destacando-se entre eles os flavonoides, os taninos e os tocoferóis (Pimentel et al.,2005).

Em se tratando de produtos cárneos, tem se observado que o alecrim e o orégano possuem alta capacidade antioxidante, sendo hoje os principais antioxidantes naturais utilizados na preservação da oxidação lipídica na indústria. As substâncias normalmente encontradas no extrato de alecrim são o ácido rosmarínico, carnosol e o ácido carnósico (Araújo, 2008) e no orégano, vários compostos fenólicos têm sido encontrados tais como os glucosídeos, ácidos fenólicos e derivados terpenos (Benzaquen, 2009).

Porém, o poder antioxidante de frutas e vegetais pode ser limitado pela quantidade de compostos presentes e também pelos meios extrínsecos e intrínsecos a sua formação, tais como condições climáticas, solo, variedades e cultivares (Melo et al., 2008). Portanto, mesmo sendo uma boa fonte de compostos antioxidantes, o emprego de extratos tem várias limitações, entre elas a dificuldade de padronização e a diferença de potencial antioxidante devido aos fatores citados, manejo diferenciado da matéria-prima e diferentes processos de extração (Velasco, 2005).

\subsection{Compostos Fenólicos em plantas}

Os compostos fenólicos são originados do metabolismo secundário das plantas, sendo essenciais para a sua reprodução e crescimento, e se formam em condições de estresse térmico ou hídrico, em casos de infecções, ferimentos e radiações ultravioleta (Naczk et al., 2004). Quimicamente, os fenólicos são definidos como substâncias que possuem anel aromático com um ou mais substituintes hidroxílicos, incluindo seus grupos funcionais, e possuem estrutura variável sendo, assim, multifuncionais (Lee et al., 2005). Existem cerca de cinco mil fenóis, dentre eles, destacam-se os flavonóides, ácidos fenólicos, fenóis simples, cumarinas, taninos, ligninas e tocoferóis (Shahidi et al.,1995). De acordo com Harborne et al. (1999) a diversidade estrutural dos compostos fenólicos deve-se à grande variedade de combinações que acontecem na natureza e os compostos resultantes são chamados de 
polifenóis. A tabela 1.1 apresenta as principais classes e estrutura química de compostos fenólicos encontrados em plantas.

Os ácidos fenólicos podem ser separados em dois grupos: derivados do ácido hidroxibenzóico e derivados do ácido hidroxicinâmico (Figura 1.4). Os ácidos hidroxibenzóicos incluem os ácidos gálico, p-hidroxibenzóico, protocatecuico, vanílico e siríngico, que têm estrutura comum (C6-C126); enquanto os ácidos hidroxicinâmicos são compostos aromáticos com três carbonos que formam uma cadeia lateral (C6-C3), como os ácidos caféico, ferúlico, p-cumárico e sináptico (Bravo et al., 1998).

Tabela 1.1: Classe dos compostos fenólicos em plantas (adaptado de Angelo \& Jorge, 2007)

\begin{tabular}{ll}
\hline Classe & Estrutura \\
\hline Fenólicos simples, benzoquinonas & $\mathrm{C}_{6}$ \\
Ácido hidroxibenzóico & $\mathrm{C}_{6}-\mathrm{C}_{1}$ \\
Acetofenol, ácidos fenilacéticos & $\mathrm{C}_{6}-\mathrm{C}_{2}$ \\
Ácidos hidroxicinâmicos, fenilpropanóides & $\mathrm{C}_{6}-\mathrm{C}_{3}$ \\
Nafitoquinonas & $\mathrm{C}_{6}-\mathrm{C}_{4}$ \\
Xantonas & $\mathrm{C}_{6}-\mathrm{C}_{1}-\mathrm{C}_{6}$ \\
Estilbenos, antoquinonas & $\mathrm{C}_{6}-\mathrm{C}_{2}-\mathrm{C}_{6}$ \\
Flavonóides, isofalvonóides & $\mathrm{C}_{6}-\mathrm{C}_{3}-\mathrm{C}_{6}$ \\
Lignanas, neolignanas & $\left(\mathrm{C}_{6}-\mathrm{C}_{3}\right)_{2}$ \\
Biflavonóides & $\left(\mathrm{C}_{6}-\mathrm{C}_{3}-\mathrm{C}_{6}\right)_{2}$ \\
Ligninas & $\left(\mathrm{C}_{6}-\mathrm{C}_{3}\right)_{\mathrm{N}}$ \\
Taninos condensados & $\left(\mathrm{C}_{6}-\mathrm{C}_{3}-\mathrm{C}_{6}\right)_{\mathrm{N}}$ \\
\hline
\end{tabular}


a)<smiles>[R]c1cc(C(=O)O)cc([R])c1O</smiles>

Ácido p-hidroxibenzóico: $\mathrm{R}_{1}=\mathrm{R}_{2}=\mathrm{H}$

Ácido protocatecuíco: $\mathrm{R}_{1}=\mathrm{OH}, \mathrm{R}_{2}=\mathrm{H}$

Ácido vanílico: $\mathrm{R}_{1}=\mathrm{OCH}_{3}, \mathrm{R}_{2}=\mathrm{H}$

Ácido siríngico: $\mathrm{R}_{1}=\mathrm{R}_{2}=\mathrm{OCH}_{3}$

b)<smiles>[R]c1cc(/C=C/C(=O)O)cc([R])c1O</smiles>

Ácido p-cumárico: $\mathrm{R} 1=\mathrm{R} 2=\mathrm{H}$

Ácido caféico: $\mathrm{R} 1=\mathrm{OH}, \mathrm{R} 2=\mathrm{H}$

Ácido ferúlico: $\mathrm{R} 1=\mathrm{OCH} 3, \mathrm{R} 2=\mathrm{H}$

Figura 1.4- Estrutura química dos ácidos hidroxibenzóicos (a) e hidroxicinâmicos (b) (adaptado de Angelo \& Jorge, 2007).

Segundo Podsedek et al. (2007) e Kyngmi et al. (2008) os compostos fenólicos podem agir como antioxidantes das seguintes formas:

- Interrompendo a reação de propagação dos radicais livres na oxidação lipídica;

- Modificando o potencial de oxirredução do meio;

- Combatendo os radicais livres através da doação de um átomo de hidrogênio de um grupo hidroxila $(\mathrm{OH})$ da sua estrutura aromática

- Atuando como quelantes de metais de transição, como o $\mathrm{Fe} 2+$ e o $\mathrm{Cu}+$;

- Reparando a lesão das moléculas atacadas por radicais livres. 
Os fenólicos interagem com o radical peroxil, por terem menos energia do que outros radicais e por serem os mais prevalentes na autoxidação. Além de prevenir a oxidação dos alimentos, quando incorporado na alimentação humana, os compostos fenólicos também são capazes de reduzir o risco de desenvolvimento de patologias, como a arteriosclerose (Namiki,1990) e o câncer (Ramarathnam et al., 1990)

\subsection{Extrato de Goiaba (Psidium guajava L.)}

De acordo com a AGRIANUAL (2010), no Brasil, 14.998 hectares são cultivados com goiabeiras que produziram 316.301 toneladas de frutos. Somente no Estado de São Paulo, maior produtor nacional, foram cultivados 4.236 hectares, responsáveis pela produção de 102.965 toneladas de frutos, valores que representam $28,24 \%$ da área total de cultivo e $32,55 \%$ da produção nacional. Grande parte dessa produção é destinada para fabricação de sucos, doces e geleias, gerando uma grande quantidade de resíduos formada principalmente pelas sementes e casca da fruta.

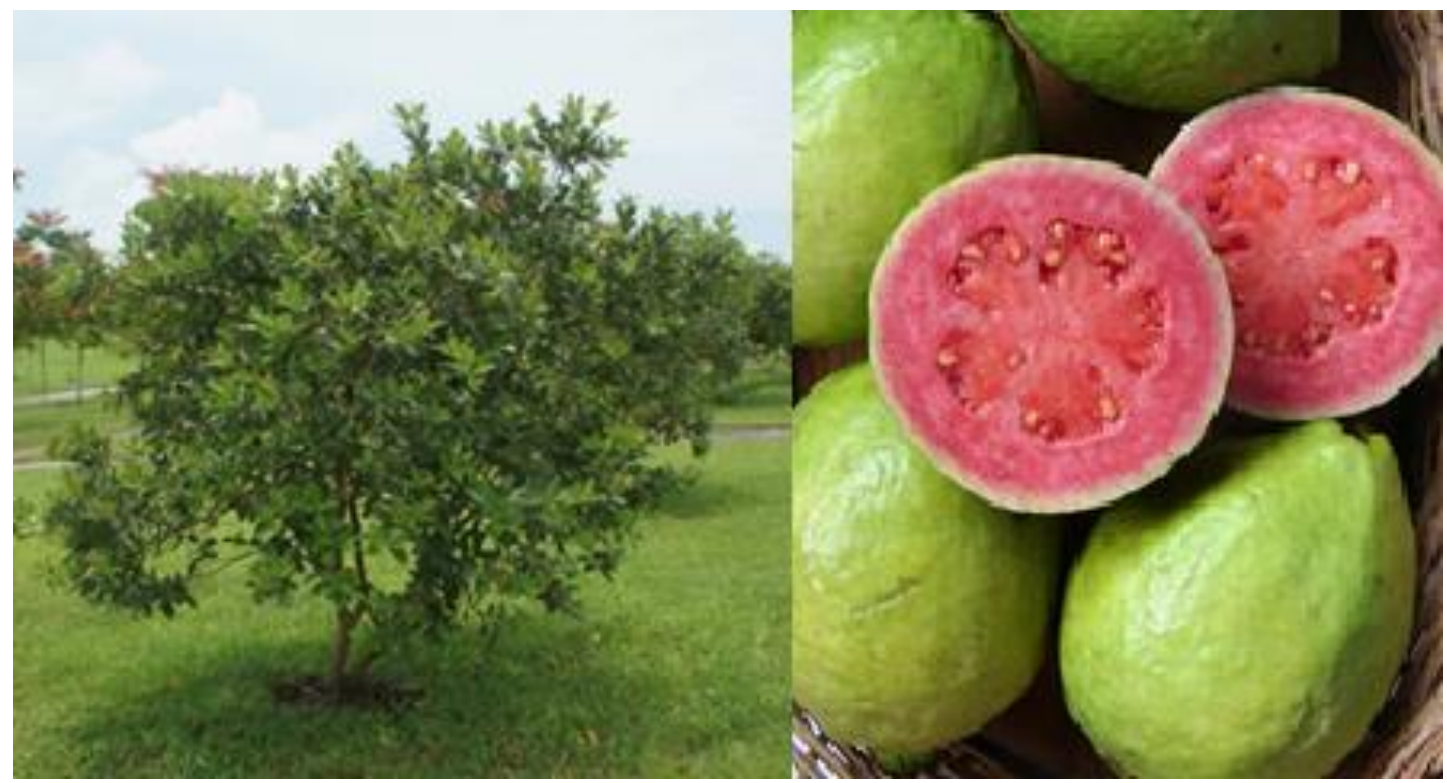

Figura 1.5: Árvore Psidium guajava e seu fruto (goiaba). Fonte: www.plantsrescue.com e www.portalagropecuario.com.br

P. guajava (L.), conhecida como "goiabeira", é um arbusto ou árvore esgalhada, podendo atingir $8 \mathrm{~m}$ de altura, sendo encontrada do México até São Paulo. A goiaba pertence à família Myrtaceae, ao gênero Psidium, originária da América Central, é de distribuição 
vasta e bastante antiga, com mais de 70 gêneros e de 2.800 espécies. (Poll et al., 2011). Comumente conhecida como guayabo na Espanha e guava nos Estados Unidos, é frequentemente cultivada como alimento por ser uma fruta agradável, que também é utilizada na produção de geleias, sorvetes, sucos, vinhos, queijos e outros (Lozoya et al., 2002). A fruta é uma baga, que consiste em um pericarpo e uma polpa com numerosas sementes pequenas (Escrig et al., 2001). Existem dois tipos mais comuns: a vermelha e a branca, sendo a vermelha mais saborosa e nutritiva, e a mais produzida no Brasil. Ela pode ser cultivada a partir das sementes e possui quantidade regular de ácidos, açúcares e pectinas.

Souza et al., 2011 estudando a composição fenólica de frutas verificou que a goiaba possui cerca de $644 \mathrm{mg} / 100 \mathrm{~g}$ de carotenoides, 3,2 mg/100g de antocianinas, 1,06 mg/100g de flavonoides e $75,90 \mathrm{mg} / 100 \mathrm{~g}$ de vitamina $\mathrm{C}$.

Os principais constituintes antioxidantes da goiaba são taninos, flavonóides, óleos essenciais, álcoois sesquiterpenóides e ácidos triterpenóides. As partes utilizadas da planta são a casca, brotos, folhas e raízes. Possui atividade antimicrobiana, antimutagênica e atividade hipoglicêmica, dentre outras (Gondim et al., 2006; Amaral et al., 2006). Na medicina popular é utilizada para cólicas, colite, diarreia (Vendruscolo et al., 2005; Tôrres et al., 2005; Oliveira et al., 2007; Agra et al., 2007). Compostos fenólicos, como myricetin e apigenina (Miean \& Mohamed, 2001), o ácido elágico, antocianinas e (Misra \& Seshadri, 1968) também são encontrados em níveis elevados nos frutos. 
CAPÍTULO 2

USO DO EXTRATO DE GOIABA (Psidium guajava L.) NA PROTEÇÃO DA CARNE DO PEITO DE FRANGO SOB RESFRIGERAÇÃO E CONGELAMENTO 


\section{RESUMO}

Este estudo teve como objetivo avaliar o potencial antioxidante do extrato de goiaba na conservação de almôndegas de peito de frango armazenadas em resfriamento e congelamento, em comparação com um antioxidante sintético. O extrato de goiaba foi obtido de indústria extrativista e foi quantificado a composição em fenólicos totais e a capacidade antioxidante in vitro (DPPH) em diferentes solventes e in vivo utilizando um modelo aplicado a almôndegas de carne de frango armazenada sob refrigeração e congelamento. A composição fenólica média obtida para o extrato de goiaba foi de 52,22 mg GAE/g e a capacidade antioxidante in vitro foi de $80 \%$ em relação à solução referência e utilizando água como solvente. Para o acompanhamento da oxidação lipídica da carne de frango foram feitas almôndegas $(30 \mathrm{~g} \pm 0,5 \mathrm{~g})$ adicionadas de $5 \%$ de sal e divididas em 5 tratamentos com adição de antioxidantes na carne: CONT (sem adição de antioxidantes); 0,5EG (0,5\% de extrato de goiaba); $1,0 \mathrm{EG}$ ( $1 \%$ de extrato de goiaba); $1,5 \mathrm{EG}$ ( $1,5 \%$ de extrato de goiaba); BHT (0,2\% de BHT). Duas almôndegas por tratamento foram submetidas a análises de TBARS (Thiobarbituric Acid Reactive Substances) em duplicata a cada 2 dias para as amostras armazenadas sob resfriamento $\left(4^{\circ} \mathrm{C}\right.$ por 8 dias) ou mensalmente para as amostras armazenadas sob congelamento $\left(-12^{\circ} \mathrm{C}\right.$ por 4 meses $)$ para determinar o acúmulo de compostos de ranço durante o período de armazenamento. Os resultados foram analisados utilizando o teste de TUKEY para a comparação das médias, com nível de significância de 5\%, e foi feita análise de regressão comparando o tratamento sem extrato com os tratamentos com níveis crescentes de EG, utilizando o Mixed do SAS Enterprise Guide 5.1 (SAS Inc, Cary, NC,USA). A adição dos antioxidantes reduziu significativamente $(\mathrm{P}<0,05)$ a formação de compostos de ranço nas almôndegas de carne de frango, em comparação com as amostras CONT, independente do tipo de antioxidante (natural ou sintético) e das dosagens de EG aplicadas. Dentre as concentrações aplicadas do $\mathrm{EG}$, o tratamento 1,5EG foi o tratamento mais eficiente $(\mathrm{P}<0,05)$ na proteção das amostras armazenadas em refrigeração e congelamento, sendo melhor que o antioxidante sintético BHT. Além disso essa concentração está muito próxima das estimadas pelas regressões obtidas para o ensaio refrigerado (1,5EG) e congelado (1,77EG). Em conclusão, o extrato de goiaba parece ser um substituto aos antioxidantes sintéticos em produtos cárneos de frango.

Palavras-Chave: extrato natural, oxidação, peito de frango, Psidium guajava, TBRAS 


\begin{abstract}
This study aimed to evaluate the antioxidant potential of guava extract on the conservation of chicken breast meatballs stored chilled and frozen, compared with a synthetic antioxidant. The guava extract (EG) was obtained from extractive industries and was quantified for the total phenolic composition and the antioxidant capacity in vitro (DPPH) in different solvents and in vivo using a chicken meat balls under chilled and frozen storage. The average of total phenolic content was $52.22 \mathrm{mg} \mathrm{GAE} / \mathrm{g}$, the in vitro antioxidant capacity was $80 \%$ compared to the reference solution and using water as solvent. To monitor the lipid oxidation of chicken breast or thigh meat, meatballs were made $(30 \mathrm{~g} \pm 0.5 \mathrm{~g})$ with the addition of $0.5 \%$ food-grade salt and divided into 5 treatments: CONT (no antioxidant); 0.5EG (0.5\% EG); 1.0EG (1\% EG); 1.5EG (1.5\% EG); BHT (0.2\% BHT). Two meatballs per treatment were analysed to quantify TBARS (Thiobarbituric Acid Reactive Substances) in duplicate each 2 days for chilled storage $\left(4{ }^{\circ} \mathrm{C}\right.$ for 8 days) or monthly for frozen storage $\left(-12{ }^{\circ} \mathrm{C}\right.$ for 4 months) to evaluate the accumulation of secondary lipid oxidation compounds during the storage period. Averages were compared using the Tukey test with 5\% significance level and regression analysis was performance to compare treatments with increasing levels of EG using the Mixed SAS Enterprise Guide 5.1 (SAS Inc., Cary, NC, USA). The addition of the antioxidant significantly reduced $(\mathrm{P}<0.05)$ the formation of rancid compounds in chicken meat balls, when compared to the CONT samples, regardless the type of antioxidant used (natural or synthetic) and EG doses applied. Among the concentrations of EG, 1.5EG was the most effective $(\mathrm{P}<0.05)$ treatment to protect both chilled or frozen meatballs, even when compared to the synthetic antioxidant BHT. Also, this concentration was very close to those estimated by linear regressions obtained for chilled test (1,5\% EG) and frozen test $(1,77 \%$ EG). In conclusion, the guava extract appears to be na effective replacement for synthetic antioxidant in breast meat products.
\end{abstract}

Keywords: natural extract, oxidation, chicken breast, Psidium guajava, TBRAS 


\section{INTRODUÇÃO}

O Brasil atualmente é o maior exportador de carne de frango do mundo. Em 2014 exportou 4.009 mil toneladas e é o terceiro maior produtor de carne de frango, ficando atrás apenas dos EUA e da China. O consumo per capita no país aumentou nos últimos dez anos passando de 33,89 kg/hab em 2004 para 42,78 kg/hab em 2014 (ABPA, 2015).

Porém, o curto tempo de prateleira da carne de frango, devido sua composição predominante de lipídios insaturados (altamente susceptíveis a oxidação) (Almeida et al., 2013), faz com que seja necessário o uso de antioxidantes, principalmente em produtos industrializados produzidos a base de carne de frango, como: hambúrgueres, almôndegas e embutidos em geral. Estudos comprovam que o uso de antioxidantes sintéticos pode acarretar em problemas de saúde como o favorecimento de hemorragias (Takahashi \& Hiraga, 1978). Além disso, hoje existe uma tendência entre os consumidores em dar preferência por produtos naturais, ditos mais saudáveis e confiáveis (Govaris et al., 2010).

Com isso, faz-se necessário encontrar alternativas ao uso dos antioxidantes sintéticos, assim agregando valor aos produtos e abrangendo um maior público consumidor. $\mathrm{O}$ uso de algumas plantas como o alecrim e o alho já são difundidos em literatura como ótimos antioxidantes naturais. Sabe-se que algumas frutas também são ricas em compostos fenólicos e em taninos, o que lhes confere um alto poder antioxidante (Pimentel et al., 2005).

A goiaba é produzida pela Psidium Guajava, conhecida como "goiabeira" e seus principais constituintes com atividade antioxidante são taninos, flavonóides, óleos essenciais, álcoois sesquiterpenóides e ácidos triterpenóides (Tôrres et 
al., 2005; Vendruscolo et al., 2005; Corrêa,Gondim et al., 2006; Amaral et al., 2006; Oliveira et al., 2007; Agra et al., 2007).

Assim, o objetivo desse experimento foi avaliar a capacidade antioxidante do extrato da goiaba como antioxidante natural na conservação de almôndegas de peito de frango em refrigeração e congelamento, em comparação com um antioxidante sintético. 


\section{MATERIAIS E MÉTODOS}

\subsection{Caracterização do extrato de goiaba}

O extrato de Psidium guavaja L. em pó, que foi doado pela UFG, foi feito a partir de resíduos da fruta compostos por casca, poupa e sementes provenientes de indústria de fabricação de doces. Inicialmente foi efetuada a secagem do resíduo úmido em estufa ventilada a temperatura de $40^{\circ} \mathrm{C}$ por três dias. Depois, o resíduo seco foi moído em moinho tipo faca obtendo-se o extrato em pó, que foi usado neste projeto.

As análises para caracterização da composição fenólica total e da atividade antioxidante in vitro do extrato foram efetuadas no Laboratório de Nutrição Animal da FAV/UnB (Universidade de Brasília) localizado na Fazenda Água Limpa, conforme descrito a seguir.

\subsection{Fenólicos Totais}

Para a determinação da composição em fenólicos totais foi utilizado o método espectrofotométrico de Folin-Ciocalteau descrito por Singleton et al. (1999), utilizando ácido gálico como padrão. $\mathrm{O}$ extrato de goiaba foi diluído em água destilada, etanol e acetona $(0,5$ $\mathrm{ml}$, com três repetições), com a finalidade de determinar o melhor meio de extração, depois as diluições obtidas foram misturadas em 2,5 mL de Folin-Reagente de Ciocalteu (Merck 9001, Darmstadt, Alemanha). Após três segundos, 7,5 ml de solução de carbonato de sódio a 20\% foi adicionado e a solução foi misturada e diluída com água em um volume final de $50 \mathrm{~mL}$. Após duas horas no escuro, as absorvências das amostras foram medidas a $765 \mathrm{~nm}$ usando um espectrofotômetro da marca GEHAKA (modelo UV-340G). 
A curva padrão foi construída utilizando o ácido gálico nas concentrações de $10 \mu \mathrm{g} / \mathrm{ml}$ a $500 \mu \mathrm{g} / \mathrm{ml}$. O conteúdo total de fenólico foi expresso em $\mathrm{mg}$ de equivalente de ácido gálico por grama de extrato adicionado (mg GAE/g).

\subsection{DPPH}

$\mathrm{O}$ extrato liofilizado de goiaba foi colocado em tubo erlenmeyer de $50 \mathrm{ml}$ na proporção de $1 \mathrm{~g} / 50 \mathrm{ml}$ (água destilada, etanol ou acetona), tampados e colocados em mesa agitadora ETHICHNOLOGY durante 40 minutos a velocidade $140 \mathrm{rpm}$. Antes do início das determinações, o material passou por filtragem em papel de filtro comum para retirada do precipitado.

Para determinação da atividade sequestrante de radicais livres do extrato nos diferentes meios de extração, foi utilizado o potencial de inibição da oxidação com uso do radical 2,2-difenil-1-picrilidrazil (DPPH) pelo método de Mensor et al. (2001), em que a atividade anti-radical é determinada na forma de \% de inibição (PI) calculada através da taxa de declínio da absorbância da solução de DPPH dos extratos e padrões após 45 minutos de reação em relação à solução referência (DPPH em etanol), de acordo com a fórmula:

AA\% (atividade antioxidante) ou capacidade de sequestro (scavenging):

$$
\mathrm{AA}(\%)=100-\{[(\mathrm{AA}-\mathrm{AB}) \times 100] / \mathrm{AC}\}
$$

\subsection{Preparo e armazenamento das almôndegas de peito de frango}

No dia 03/09/2014 foram adquiridos 7,0 kg de peito resfriado de frango desossado e sem pele (data de fabricação: dia 03/09/2014) em supermercado na cidade de Brasília/DF. A carne foi moída em processador de alimentos e adicionada de 0,5\% de sal de cozinha. Após ser homogeneizada manualmente, a carne foi separada em cinco porções de $1,2 \mathrm{~kg}$ aproximadamente, sendo que o excedente foi embalado a vácuo e congelado para posterior análise bromatológica. Nas cinco porções foram aplicados os tratamentos com antioxidantes naturais (extrato de goiaba liofilizado) ou sintético (BHT), sendo:

- CONT: sem adição de antioxidantes (controle negativo)

- BHT: adição de 0,2\% do antioxidante sintético BHT (controle positivo) 
- $0,5 \mathrm{EG}$ : adição de $0,5 \%$ de extrato em pó de goiaba (EG)

- 1,0EG: adição de 1,0\% de extrato em pó de goiaba (EG)

- 1,5EG: adição de 1,5\% de extrato em pó de goiaba (EG)

Após completa homogeneização, foram feitas almôndegas de $30 \mathrm{~g}$ (+- 0,5 g) cada, que foram embaladas a vácuo e pré-cozidas em banho-maria a $100{ }^{\circ} \mathrm{C}$ por 10 min e resfriadas em água com gelo. Após resfriamento foram separadas 10 almôndegas de cada tratamento, que foram embaladas em saco permeável ao oxigênio devidamente identificados, duas amostras por saco, e armazenadas sob resfriamento em câmara fria a $4{ }^{\circ} \mathrm{C}$ por até oito dias.

Para o estudo do armazenamento sob congelamento, a uma temperatura média de -12 ${ }^{\circ} \mathrm{C}$, mais oito almôndegas foram separadas por tratamento, embaladas em saco permeável ao oxigênio, duas amostras por saco devidamente identificadas, e mantidas em congelador por até 4 meses.

\subsection{Análise das amostras resfriadas}

Durante o período de armazenamento em câmara fria, foram coletadas duas amostras de cada tratamento, que foram analisadas em duplicata, com a finalidade de acompanhar a oxidação lipídica da carne com o método de TBARS (Thiobarbituric acid reactive substances). As análises foram feitas em cinco dias correspondendo ao dia 0 (03/09/2014), ao dia $2(05 / 09 / 2014)$, ao dia $4(07 / 09 / 2014)$, ao dia $6(09 / 09 / 2014)$ e ao dia $8(11 / 09 / 2014)$ de armazenamento. Os valores médios de TBARS foram expressos em $\mu$ mol de malonaldeído por quilograma $(\mathrm{MDA} / \mathrm{kg})$ de amostra.

\subsection{Análise das amostras congeladas}

Durante o período de armazenamento sob congelamento, foram coletadas mensalmente duas amostras de cada tratamento, que foram analisadas em duplicata, com a finalidade de acompanhar a oxidação lipídica da carne com o método de TBARS (Thiobarbituric acid reactive substances). As análises no primeiro dia (03/9/2014) foram efetuadas com as almôndegas antes do congelamento (DIA 0), com um mês de armazenamento (MÊS 1, dia 02/10/2014), dois meses (MÊS 2, dia 29/10/2014), três meses (MÊS 3, dia 01/12/2014) e quatro meses de armazenamento (MÊS 4, dia 30/12/2014). Os 
valores médios de TBARS foram expressos em $\mu$ mol de malonaldeído por quilograma $(\mathrm{MDA} / \mathrm{kg})$ de amostra.

\subsection{Determinação da oxidação lipídica}

As substâncias reativas ao ácido tiobarbitúrico (TBARS) resultantes da oxidação lipídica das amostras da carne do peito de frango, foram determinadas segundo o método de Madsen et al. (1998). Para cada almôndega foram pesadas $5 \mathrm{~g} \mathrm{(+-} \mathrm{0,05} \mathrm{g),} \mathrm{em} \mathrm{duplicata,} \mathrm{em}$ tubo tipo falcon de $50 \mathrm{ml}$ e adicionado $15 \mathrm{ml}$ de solução de tricloroacético 7,5\% + Propil Galato $0,1 \%$ + EDTA $0,1 \%$ e homogeneizados no misturador tipo Ultra Turax (marca IKA), sendo filtrado em seguida com o uso de papel de filtro comum.

Em tubo falcon de $15 \mathrm{ml}$ com tampa, foi pipetado $5 \mathrm{ml}$ do filtrado e adicionado de 5 ml de solução TBA, para a formação do composto cromóforo de cor vermelha em banhomaria durante 40 minutos $\left(100^{\circ} \mathrm{C}\right)$. Em seguida as soluções foram resfriadas em água com gelo por 15 minutos para a leitura da absorbância nos comprimentos de onda de 532 e $600 \mathrm{~nm}$ usando um espectrofotômetro da marca GEHAKA (modelo UV-340G).

\subsection{Análise bromatológica da carne do peito de frango}

Para a composição bromatológica foram avaliados, em quadruplicada, a umidade (UM), matéria mineral (MN), o teor de proteína bruta (PB) e o teor de lipídios totais (LPT), na carne crua do peito.

Para o cálculo da umidade foi inicialmente obtida a matéria seca (AOAC, 1990) e, em seguida, foi determinada a umidade, através da fórmula:

$$
\text { Umidade }=100 \%-\% \text { Matéria Seca }
$$

A matéria mineral foi quantificada pelo método gravimétrico por incineração em mufla a $600^{\circ} \mathrm{C}$ por 4 horas, de acordo com a metodologia descrita por AOAC (1990). O teor de proteína bruta foi determinado pelo método de destilação e titulação ou método Kjedahl (AOAC, 1990). O teor de lipídios totais foi determinado pelo método gravimétrico utilizando solvente de éter de petróleo de acordo com metodologia de Soxhlet (AOAC, 1995). 


\subsection{Análise estatística}

O desenho experimental foi inteiramente casualizado, com um controle negativo e quatro tratamentos. Para a comparação de médias foi utilizado o teste de TUKEY com nível de significância de 5\%, e o PROC REG para análise de regressão entre o controle negativo e os tratamentos contendo os níveis crescentes de EG utilizando o Mixed do SAS Enterprise Guide 5.1 (SAS Inc, Cary, NC,USA). 


\section{RESULTADOS E DISCUSSÃO}

\subsection{Compostos Fenólicos}

A quantidade de compostos fenólicos totais do extrato de goiaba extraídos em água, etanol e acetona, estão descritos na Tabela 2.1. Pode-se observar que o extrato em água apresentou valores mais elevados $(\mathrm{p}<0,05)$ de compostos fenólicos totais, sendo 52,22 mg GAE/g de extrato, seguido do etanol com 8,24 mg GAE/g de extrato e da acetona com 1,69 mg GAE/g.

Tabela 2.1-Compostos Fenólicos Totais do extrato de goiaba em água, etanol e acetona

\begin{tabular}{cc}
\hline CONCENTRAÇÃO FENÓLICA TOTAL $(\mathrm{mgGAE} / \mathrm{g})$ \\
\hline Ågua & $52,22^{\mathrm{a}}$ \\
Etanol & $8,24^{\mathrm{b}}$ \\
Acetona & $1,69^{\mathrm{c}}$ \\
\hline
\end{tabular}

$\overline{\text { a,b,c }}$ Médias com letras diferentes na mesma coluna indicam diferença estatística significativa $(\mathrm{p}<0,05)$

Dados semelhantes foram relatados por Verma et al. (2013), avaliando o uso de extrato de goiaba em nuggets de carne de ovelha, encontraram valores de compostos fenólicos totais de 44,04 mg GAE/g, valores próximos aos encontratos no presente trabalho. Os autores sugerem ainda que os fenólicos presentes no extrato de goiaba estão diretamente associados a sua excelente capacidade antioxidante.

Por outro lado os valores encontrados são superiores aos relatados por Vieira et al. (2011), avaliando compostos fenólicos de polpa de goiaba em água e etanol. Os autores encontraram valores de fenólicos totais de 201,61 mg GAE/100 g em água e 165,07 mg GAE/100 g em álcool. Vale ressaltar que essa diferença era esperada, uma vez que os extratos são mais concentrados do que a polpa, e que de acordo com Roesler et al. (2007) a quantidade de fenólicos em frutos é maior na casca e na semente do que na polpa 
Comparado com extrato de outras frutas, como da ameixa (26,43 mg GAE/g), o de maçã $(28,66 \mathrm{mg} \mathrm{GAE} / \mathrm{g}$ ) de fenóis totais (Imeh et al.,2002) e o extrato de romã (18 mg GAE/g ) de fenóis totais (Singh et al.,2002), o extrato de goiaba mostra ser um fruto com alta quantidade de fenólicos, sendo assim um potencial produto a ser utilizado como antioxidante natural em alimentos.

\subsection{Atividade anti-radical DPPH}

Os gráficos 2.1 e 2.2, que representam os resultados de DPPH, mostram a porcentagem de inibição e a atividade antioxidante encontradas para o antioxidante sintético BHT e para o extrato de goiaba em três diferentes diluentes: água destilada, álcool e acetona, respectivamente. De acordo com os resultados de DPPH, a água destilada mostrou ser o melhor ( $p>0,05)$ meio para diluição e extração dos compostos de ação antioxidante, apresentando $81,33 \%$ de inibição e $80,43 \%$ de atividade antioxidante. Por outro lado, o extrato de goiaba diluído em etanol e acetona não apresentaram bons resultados quanto a porcentagem de inibição que foi de $16,11 \%$ e $18,91 \%$ respectivamente. Para a atividade antioxidante os resultados também foram inferiores, sendo de $15,22 \%$ para o etanol e de $14,59 \%$ para a acetona.

Diferente de outros extratos vegetais, que tem melhor diluição em compostos álcoolicos, os compostos das frutas apresentam maior polaridade, portanto são mais hidrossolúveis. Segundo Wu et al. (2004), ao avaliarem o conteúdo de polifenóis de frutas consumidas nos Estados Unidos, observaram que a fração hidrofílica possuía uma quantidade superior desses constituintes, em comparação com a porção lipofílica, o que explica a água ter sido o melhor meio de extração dos compostos fenólicos da goiaba quando comparado ao álcool e a acetona. Álem disso os melhores resultados em água são favoráveis já que este é o meio mais seguro para uso em alimentos, de acordo com Racanicci et al. (2008). 


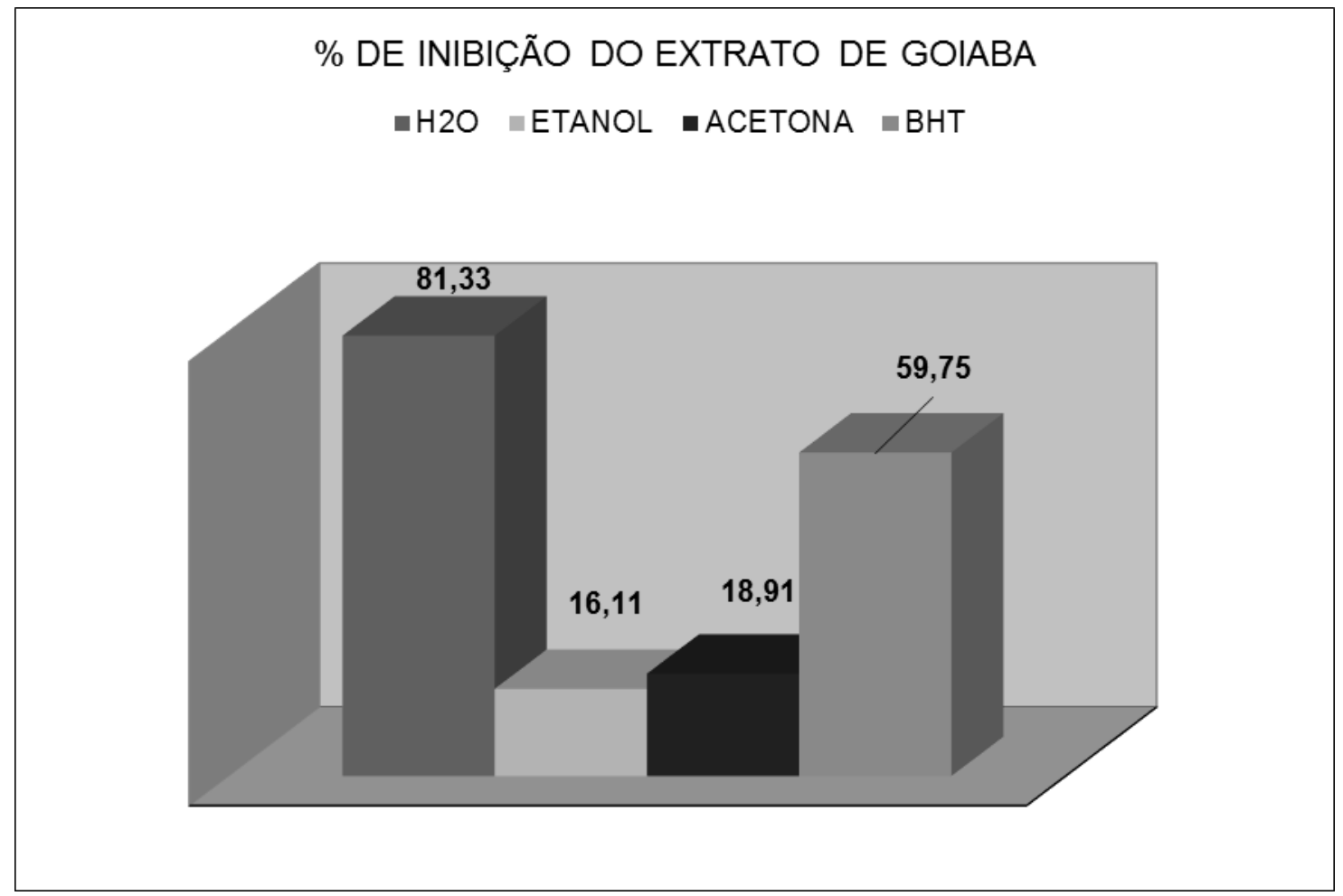

Gráfico 2.1: Porcentagem de inibição para o extrato de goiaba em água, etanol e acetona em comparação com o antioxidante BHT

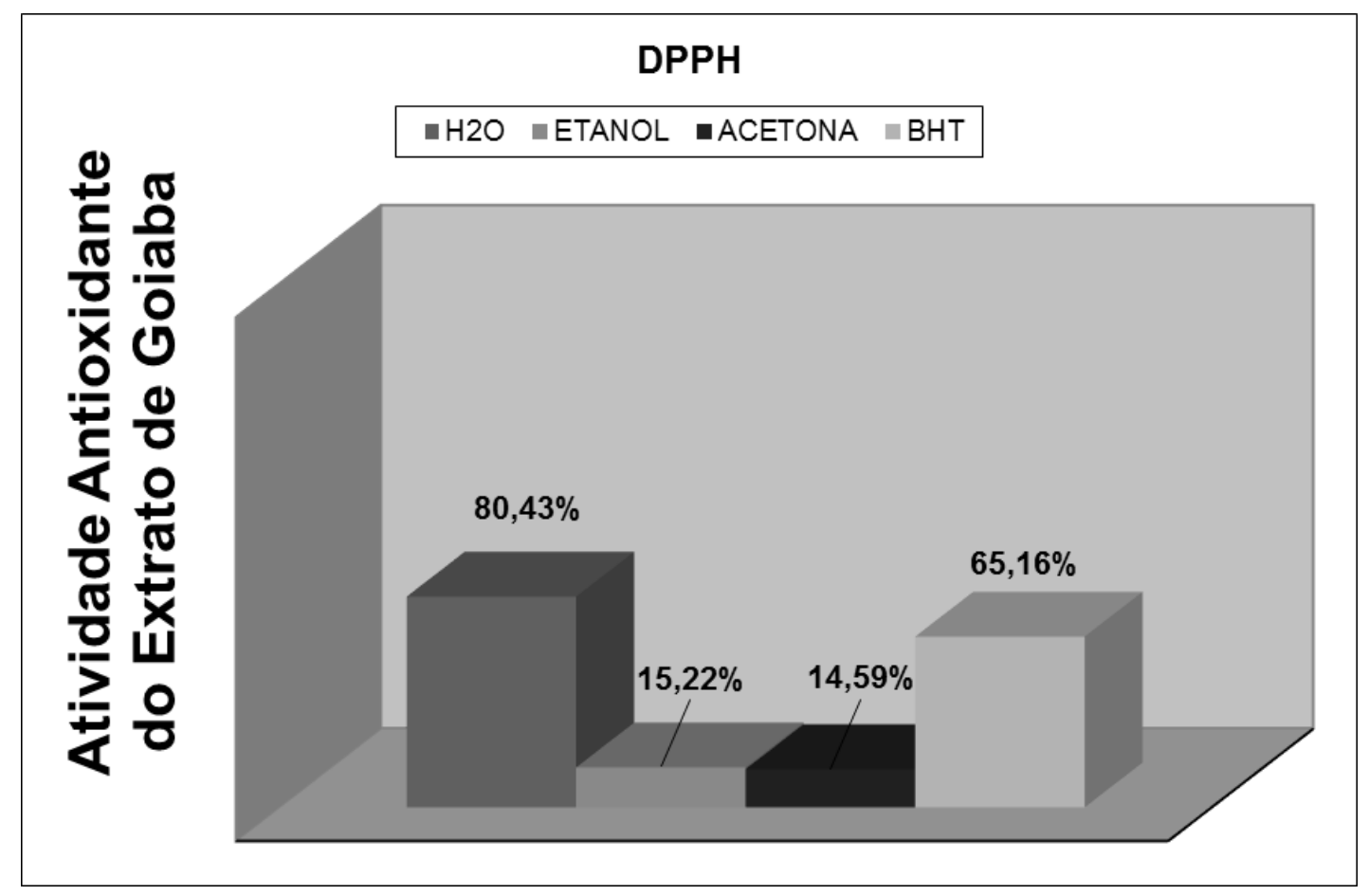

Gráfico 2.2: Atividade antioxidante para o extrato de goiaba em água, etanol e acetona, em comparação com o antioxidante BHT 
Analisando a capacidante antioxidante de extratos de frutas, Melo et al. (2008) encontraram valores médios de porcentagem de inibição para a goiaba de $80 \%$ (água) e de $50 \%$ (acetona). Já em relação a atividade antioxidante, encontraram valores de 70\% (água) e $20 \%$ (acetona), e $60 \%$ para o BHT, valores próximos aos encontrados neste trabalho. Essa alta atividade antioxidante, do extrato de goiba analisado, pode ser atribuída a grande concentração de compostos fenólicos encontradas, já que segundo Amarowicz et al. (2004) existe uma correlação direta entre a atividade antioxidante e o poder de redução de extratos de plantas com alto teor de fenóis por meio da quebra de radicais livres devido, à doação de átomos de hidrogênio.

\subsection{Composição bromatológica da carne do peito}

Os resultados de composição bromatológica da carne do peito podem ser observados na Tabela 2.2. Comparando os resultados obtidos na carne de peito de frango usada no experimento com os dados da Tabela Brasileira de Composição de Alimentos (TACO), pode-se observar que o valor de padronização para a proteína bruta é de 21,5\%, já os valores obtidos na carne analisada foram acima do padrão sendo de 23,48\%, em relação ao extrato etéreo que foi de $2,19 \%$ o padrão determinado é de 3,0\%, sendo assim uma carne relativamente menos gordurosa e com maior proporção de proteína do que o padrão determinados. Já os resultados de umidade e matéria mineral vão de acordo aos padrões determinados (NEPA, 2011).

Tabela 2.2: Médias e desvios da composição bromatológica, em porcentagem, da carne do peito de frango sem pele e valores da tabela TACO (NEPA, 2011), $(n=4)$

\begin{tabular}{ccccc}
\hline \multicolumn{4}{c}{ COMPOSIÇÃO BROMATOLÓGICA (\%) } \\
\hline & Umidade & Matéria mineral & Proteína bruta & Extrato etéreo \\
Peito frango & $74,6 \pm 0,5$ & $1,6 \pm 0,2$ & $23,5 \pm 0,6$ & $2,2 \pm 0,2$ \\
TACO & 74,8 & 1,7 & 21,5 & 3,0 \\
\hline
\end{tabular}




\subsection{Ensaio de armazenamento refrigerado}

O Gráfico 2.3 mostra os valores médios de TBARS para as amostras de carne de peito antes e depois do cozimento em banho-maria (cruas e cozidas). Nota-se que o processo de cocção realizado no peito do frango acelerou a oxidação dos lipídios, aumentando a produção dos compostos de ranço verificados nos maiores resultados de TBARS, em comparação com as amostras cruas. De acordo com Mariutti \& Bragagnolo. (2009), o cozimento aplicado a carne altera o teor de lipídios totais encontrados na carne cozida em comparação com a carne crua, aumentando o teor de lipídios em cerca de 2 a 3 vezes, devido à perda de água durante o processamento. Apesar do cozimento ter sido realizado dentro de embalagem à vácuo, foi verificada a perda de água.

Além disso o aumento de temperatura provoca na carne uma maior taxa de autooxidação, afetando a cadeia de formação de hidroperóxidos e a sua decomposição. De acordo com Regitano-D'Arce. (2006) a cada $15{ }^{\circ} \mathrm{C}$ de aumento na temperatura, a velocidade de reação dobra resultando em um aumento na concentração de radicais livres disponíveis e a disseminação de cadeias de reação.

Todos os tratamentos analisados foram capazes de controlar a formação de compostos de ranço durante o cozimento, mesmo com o processo de cozimento ocorrendo a $100{ }^{\circ} \mathrm{C}$, apresentando menores valores de TBARS em comparação ao controle ( $\mathrm{p}<0,05)$, com exceção do $0,5 E G$ que foi maior que o controle para a carne crua e cozida $(p<0,05)$. Os maiores valores de TBARS nessa concentração, não era esperada, podendo estar associada a falhas casuais no decorrer das análises, como durante a homogeneização, podendo ser amostras com uma maior quantidade de lipídios do que as demais. 


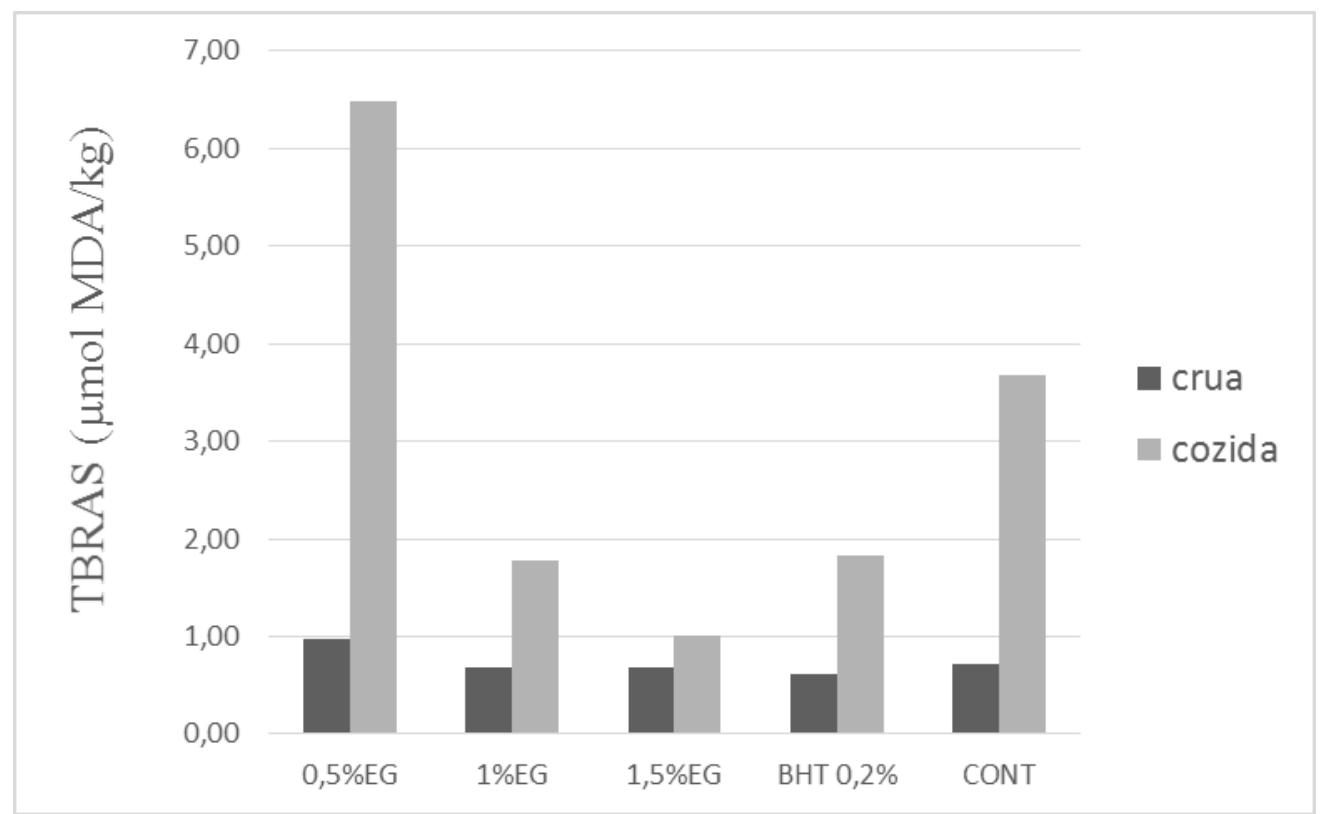

Gráfico 2.3: Acúmulo de compostos secundários da oxidação lipídica (TBARS, umol MDA/kg de carne) das almondegas de frango cruas e cozidas $(n=4)$

Os resultados médios de TBARS obtidos para as amostras cozidas e armazenadas sob resfriamento podem ser observados na Tabela 2.3 e no Gráfico 2.4. Observa-se que não foram verificadas diferenças estatisticamente significativas $(\mathrm{p}<0,05)$ entre os tratamentos aplicados no dia zero. No entanto, a partir do segundo dia de armazenamento, o acúmulo dos compostos de ranço pode ser observado pelo aumento dos valores médios de TBARS, sendo que as amostras contendo EG apresentaram valores de TBARS significativamente menores $(p<0,05)$ em todos os dias de avaliação, em comparação ao controle negativo (CONT).

A adição do BHT, com exceção do dia 6, proporcionou um menor ( $\mathrm{p}<0,05)$ acúmulo de compostos de ranço em comparação ao controle negativo (CONT), mas não em comparação com os tratamentos contendo o extrato de goiaba 1,0 e 1,5. Ao final dos 8 dias de armazenamento, a adição do BHT protegeu $(\mathrm{p}<0,05)$ os lipídios da oxidação em relação ao CONT, mas os efeitos foram mais evidentes para o uso do EG, independente da dosagem utilizada.

Vale enfatizar que o uso do BHT nos dias 6 e 8 foi menos eficaz na proteção oxidativa da carne do que o 0,5EG, assim pode-se sugerir que o uso do extrato de goiaba é mais eficaz na proteção da carne do peito de frango ao longo do tempo, quando comparado ao antioxidante sintético BHT. 
Tabela 2.3- Valores médios de TBARS ( $\mu$ mol MDA/kg de carne) em almôndegas de carne de peito pré-cozidas e armazenadas por até 8 dias a $4^{\circ} \mathrm{C}(\mathrm{n}=4)$

\begin{tabular}{cccccc}
\hline \multicolumn{5}{c}{ TEMPO DE ARMAZENAMENTO (dias) } \\
\hline CONT & 0 & $2^{2}$ & $4^{3}$ & $6^{4}$ & $8^{5}$ \\
$0,5 \mathrm{EG}$ & 3,67 & $16,74^{\mathrm{a}}$ & $26,11^{\mathrm{a}}$ & $28,86^{\mathrm{a}}$ & $38,28^{\mathrm{a}}$ \\
$1,0 \mathrm{EG}$ & 4,08 & $10,05^{\mathrm{b}}$ & $20,48^{\mathrm{b}}$ & $23,47^{\mathrm{b}}$ & $27,22^{\mathrm{c}}$ \\
$1,5 \mathrm{EG}$ & 1,78 & $5,90^{\mathrm{c}}$ & $6,75^{\mathrm{c}}$ & $8,25^{\mathrm{c}}$ & $9,6^{\mathrm{d}}$ \\
$\mathrm{BHT}$ & 1 & $1,86^{\mathrm{d}}$ & $2,33^{\mathrm{d}}$ & $3,53^{\mathrm{d}}$ & $2,87^{\mathrm{e}}$ \\
$\mathrm{CV}(\%)$ & 1,83 & $11,72^{\mathrm{b}}$ & $20,59^{\mathrm{b}}$ & $28,02^{\mathrm{a}}$ & $31,36^{\mathrm{b}}$ \\
$\mathrm{P}$ & 12,8 & 19,9 & 7,1 & 9,8 & 13,3 \\
$\mathrm{R}^{2}$ & $<0,0001$ & $<0,0001$ & $<0,0001$ & $<0,0001$ & $<0,0001$ \\
\hline
\end{tabular}

a,b,c Médias com letras diferentes na mesma coluna indicam diferença estatística significativa $(p<0,05)$ Análise de regressão entre CONT e tratamentos com níveis de EG:

$\mathrm{Y}^{2}=14,64552-8,68479 \mathrm{x} ; \mathrm{Y}^{3}=24,91462-15,85012 \mathrm{x} ; \mathrm{Y}^{4}=29,76971-18,28789 \mathrm{x} ; \mathrm{Y}^{5}=36,36963-23,38407 \mathrm{x}$;

Assim, observando o Gráfico 2.4 pode-se constatar que ao longo dos 8 dias de armazenamento, a adição do EG, independente das dosagens, protegeu eficientemente os lipídios da carne do peito, uma vez que os resultados de TBARS foram significativamente menores $(\mathrm{p}<0,05)$, em comparação ao CONT e ao BHT. A alta capacidade de antioxidação da goiaba também é demostrada por Araújo et al., (2014) que avaliando, in vitro, as capacidades antioxidantes de resíduos da goiaba, da manga e da acerola, obtiveram resultados superiores em todas as análises para a goiaba quando comparada as outras frutas.

Vale ressaltar que o aumento das dosagens de EG foi acompanhado por reduções significativas $(\mathrm{p}<0,05)$ no acúmulo dos compostos de ranço, semelhante aos resultados encontrados por Joseph et al. (2012) e Madsen (1998) para carne de suínos e ovinos, respectivamente. $\mathrm{E}$ que os tratamentos 1,0EG e 1,5EG foram mais eficientes $(\mathrm{p}<0,05)$ em preservar os lipídios da carne do que o antioxidante sintético utilizado (BHT), durante todo o período de armazenamento.

Porém, Verma et al. (2013) utilizando extrato de goiaba a $0,5 \%$ e $1,0 \%$ e BHT a $1 \%$, em nuggets de carne ovina armazenadas por 15 dias, não obtiveram diferenças significantes entre esses tratamentos, diferente do resultado obtido no presente trabalho, em que o uso de $1 \%$ e $1,5 \%$ de EG foram mais eficientes do que o BHT, certamente essa diferença pode ter ocorrido devido ao uso de uma menor dosagem de BHT (0,2\% de BHT). 


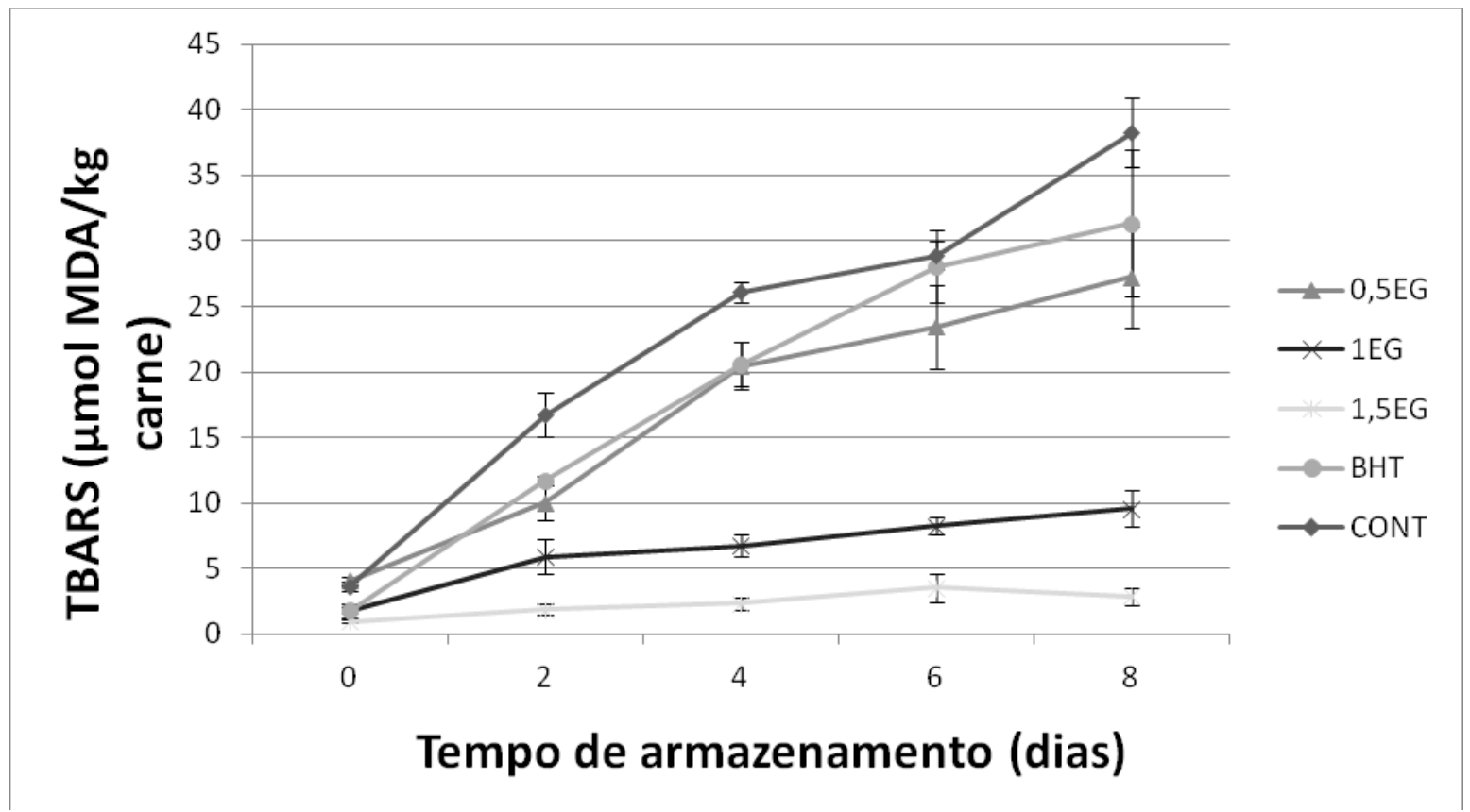

Gráfico 2.4: Valores de TBARS ( $\mu$ mol MDA/kg ) das almôndegas pré-cozidas de peito de frango armazenadas sob refrigeração durante 8 dias, contendo diferentes dosagens de extrato de goiaba ou BHT

Verificamos ainda que, a partir do segundo dia de armazenamento, à medida que a dosagem do EG aumentou, maiores $(\mathrm{p}<0,05)$ foram os efeitos positivos na proteção das almôndegas contra a oxidação lipídica, o que pode ser confirmado pelas regressões lineares apresentadas na Tabela 2.3.

Para predizer a concentração ótima de EG a ser empregada para que a formação de compostos de ranço seja zero, foram utilizadas as equações com o melhor coeficiente de determinação: $\mathrm{R}^{2}=0,9412$ (DIA 6) e $\mathrm{R}^{2}=0,9322$ (DIA 8), sendo que $\mathrm{y}=$ valor de TBARS e $\mathrm{x}=$ porcentagem de EG. Assim, considerando $\mathrm{Y}=0 \mu \mathrm{mol} \mathrm{MDA} / \mathrm{kg}$, pode-se estimar os valores ótimos de 1,62\% na regressão do DIA 6 e 1,55\% de EG no DIA 8. Esses valores foram próximos da maior concentração de EG utilizada neste experimento.

Estudos sensoriais com uso de resíduos de goiaba em produtos cárneos não foram encontrados na literatura, porém, o uso de $5 \%$ e $10 \%$ em substituição a farinha na elaboração de produtos de panificação recebeu uma boa aprovação sensorial , (Sousa et al.,2014), assim como na adição de 1,5\% e 2,0\% em biscoitos (Uchoa et al.,2009). 
Tendo em vista a utilização do extrato de goiaba em produtos a base de carne de frango, como antioxidante natural, é necessária a realização de análises sensoriais futuras, para determinar se a dosagem ótima encontrada traria prejuízos ao sabor do produto final.

\subsection{Ensaio de armazenamento congelado}

A Tabela 2.4 apresenta os valores de TBARS das almôndegas de peito de frango armazenadas sob congelamento ao longo de 4 meses. No dia 0 não houve diferença estatística $(p<0,05)$ entre os tratamentos, no entanto, já a partir do primeiro mês de armazenamento, as amostras do controle apresentaram maiores $(\mathrm{p}>0,05)$ quantidades de compostos de ranço em relação aos demais tratamentos até o final do período de armazenamento.

Ao final do MÊS 1 de armazenamento, todos os tratamentos conservaram a carne em relação ao CONT porém o tratamento que melhor conservou as almôndegas congeladas foi o 1,5 EG, sendo que os tratamentos 0,5 EG e 1 EG não diferiram estatisticamente do BHT. Já a partir do MÊS 2 de congelamento o 1,5EG foi o melhor na conservação das almondegas congeladas em relação aos outros tratamentos, sendo seguido de 1,0EG; 0,5EG e o antioxidante sintético BHT.

No MÊS 3 não houve diferença estatística significativa $(\mathrm{p}<0,05)$ entre o BHT e os tratamentos com extrato de goiaba, com exceção do $1,5 \mathrm{EG}$ que apresentou menor $(\mathrm{p}<0,05)$ formação de compostos de ranço. No MÊS 4 todos os tratamentos com extrato de goiaba foram melhores $(\mathrm{p}<0,05)$ que o BHT, esta excelente ação antioxidante pode ser explicada devido a capacidade do extrato de goiaba em eliminar radicais livres, e também de inibir a formação de radicais de hidroxila, pela ação de antioxidantes presentes em sua composição tais como quercetina, carotenóides, Vitamina C e polifenóis presentes (Fasola et al.,2011). 
Tabela 2.4- Valores médios de TBARS ( $\mu$ mol MDA/kg de carne) em almôndegas de carne de peito pré-cozidas e congeladas por até 4 meses $(n=4)$

TEMPO DE ARMAZENAMENTO (MESES)

\begin{tabular}{cccccc}
\hline & 0 & $1^{2}$ & $2^{3}$ & $3^{4}$ & $4^{5}$ \\
\hline CONT & 3,67 & $8,37^{\mathrm{a}}$ & $8,08^{\mathrm{a}}$ & $13,5^{\mathrm{a}}$ & $12,09^{\mathrm{a}}$ \\
$0,5 \mathrm{EG}$ & 4,08 & $2,98^{\mathrm{b}}$ & $4,17^{\mathrm{c}}$ & $3,38^{\mathrm{b}}$ & $4,78^{\mathrm{c}}$ \\
$1,0 \mathrm{EG}$ & 1,78 & $1,72^{\mathrm{bc}}$ & $2,69^{\mathrm{d}}$ & $3,47^{\mathrm{b}}$ & $3,76^{\mathrm{c}}$ \\
$1,5 \mathrm{EG}$ & 1,00 & $1,06^{\mathrm{c}}$ & $1,72^{\mathrm{e}}$ & $2,03^{\mathrm{c}}$ & $3,17^{\mathrm{d}}$ \\
BHT & 1,83 & $2,48^{\mathrm{b}}$ & $5,66^{\mathrm{b}}$ & $6,11^{\mathrm{b}}$ & $7,45^{\mathrm{b}}$ \\
$\mathrm{CV}(\%)$ & 12,9 & 18,5 & 6,74 & 32,23 & 12,8 \\
P & $<0,0001$ & $<0,0001$ & $<0,0001$ & $<0,0001$ & $<0,0001$ \\
$\mathrm{R}^{2}$ & 0,47 & 0,49 & 0,89 & 0,41 & 0,75
\end{tabular}

a,b,c Médias com letras diferentes na mesma coluna indicam diferença estatística significativa $(\mathrm{p}<0,05)$

Análise de regressão entre CONT e tratamentos com níveis de EG:

$\mathrm{Y}^{2}=5,37636-3,30835 \mathrm{x} ; \mathrm{Y}^{3}=6,77730-3,72991 \mathrm{x} ; \mathrm{Y}^{4}=9,04609-4,98269 \mathrm{x}$;

$\mathrm{Y}^{5}=9,43445-5,49618 \mathrm{x}$

Outros autores também observaram redução na oxidação lipídica em carne de frango durante o congelamento, pela adição de fontes de antioxidantes naturais como Freitas et al., (2015) que usando extrato de semente e casca de manga em diferentes dosagens, sob armazenamento por 3 meses, obtiveram significativa proteção da carne e Cestari et al., (2015) que utilizando extrato de orégano em diferentes tipos de embalagem em congelamento por 150 dias, também obteve resultados favoráveis de proteção. O que mostra o crescente interesse no estudo de antioxidantes naturais em substituição aos sintéticos.

No Gráfico 2.5, pode-se observar que a adição do EG se mostrou eficaz na conservação das almôndegas de frango congeladas, assim como o BHT. No entanto, a dosagem de 1,5\% EG foi mais efetiva que o BHT e a que melhor conservou as almôndegas durante todo o período do ensaio de congelamento.

Os uso de 1EG e 1,5EG, a partir do MÊS 2, foi mais eficiente na proteção das almôndegas de frango do que o uso do BHT, diferente do que foi relatado por Norhidayah et al. (2011) que utilizando extrato de goiaba a 0,8\% e BHT 0,2 \% em bolas de carne de frango em congelamento ao longo de 3 meses, obtiveram melhores resultados de conservação com o uso do antioxidante sintético BHT. Assim pode-se sugerir que a dosagem de 0,8\% de extrato, 
apesar de promover a proteção da carne, não seria suficiente para se equiparar ao uso do BHT, já a dosagem de $1 \%$ utilizada no presente trabalho superou a proteção do BHT.

A partir do segundo dia de armazenamento, à medida que a dosagem do EG aumentou, maiores $(p<0,05)$ foram os efeitos positivos na proteção das almôndegas contra a oxidação lipídica, o que pode ser confirmado pelas regressões lineares apresentadas na Tabela 2.4.

\section{TBARS PEITO CONGELADO}

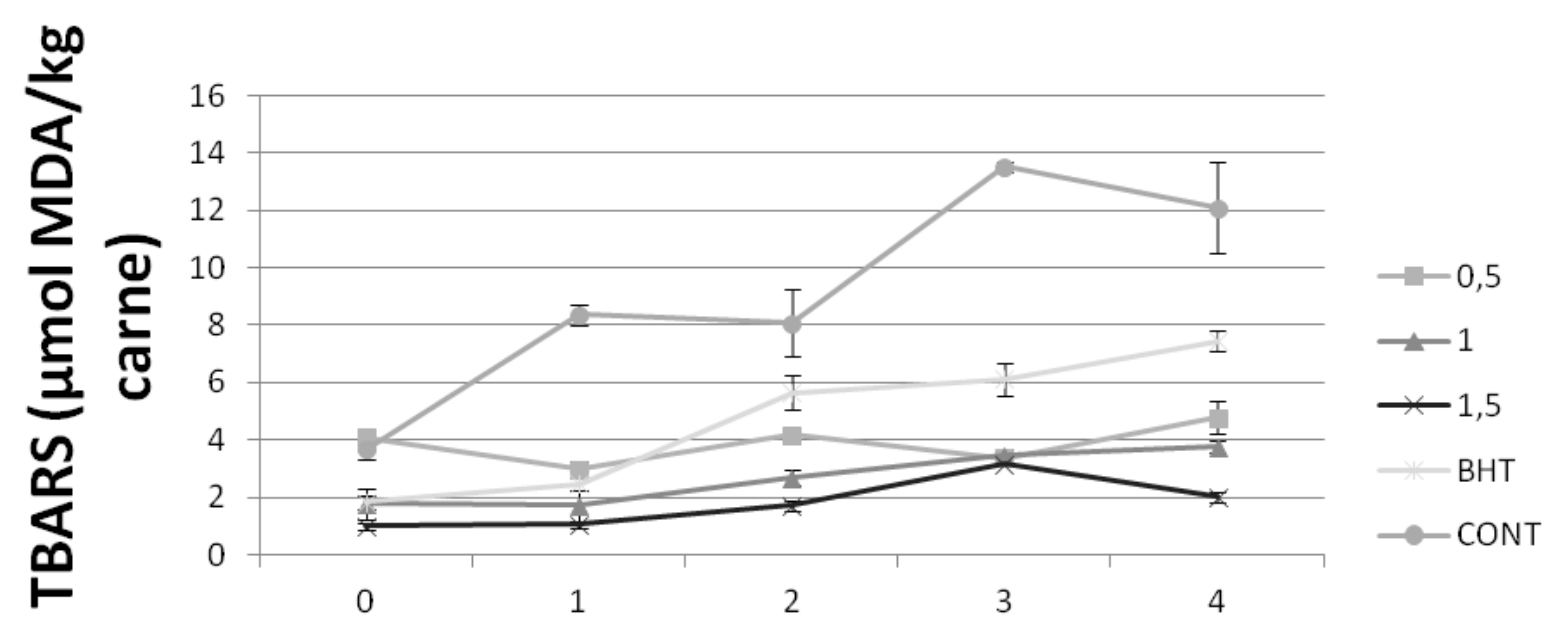

Tempo de armazenamento (meses)

Gráfico 2.5: Valores de TBARS ( $\mu$ mol MDA/kg ) em almôndegas de peito de frango congelado durante 4 meses com diferentes dosagens de extrato de goiaba e BHT.

Para estimar a concentração ótima de EG para a mínima formação de compostos de ranço, foram utilizadas as equações com o melhor coeficiente de correlação: $R^{2}=0,89$ (MÊS 2) e $R^{2}=0,75$ (MÊS 3), sendo que $Y=$ valor de TBARS e $X=$ porcentagem de EG. Assim, considerando $\mathrm{Y}=0 \mu \mathrm{mol} \mathrm{MDA} / \mathrm{kg}$, ou seja, formação zero de compostos de ranço, pode-se estimar os valores de 1,81\% (MÊS 2) e 1,71\% de EG (MÊS 4). As estimativas foram ligeriamente maiores do que para a carne refrigerada, possivelmente devido ao maior tempo de armazenamento, já que mesmo sob congelamento a oxidação dos lipidios continua ocorrendo. 


\section{CONCLUSÃO}

O uso de extrato de goiaba em todas as concentrações estudadas preservou eficientemente os lipídios das almôndegas de peito de frango pré-cozidas e armazenadas sob refrigeração e congelamento. Dentre as dosagens estudadas, 1,5\% de EG foi a concentração que proporcionou os melhores resultados, mesmo quando comparada com o antioxidante sintético BHT, valor muito próximo da concentração estimada através da regressão linear negativa para o período total de armazenamento . Assim, a utilização do extrato de goiaba na carne do peito de frango pode ser um bom substituto dos antioxidantes sintéticos na conservação de almôndegas de carne armazenadas sob refrigeração ou congelamento. 


\section{REFERÊNCIAS BIBLIOGRÁFICAS}

ABPA, Associação Brasileira de Proteína Animal. "Estatística do mercado interno e externo.", acessado em: $\quad$ http://abpa-br.com.br/setores/avicultura/mercadointerno/frango no dia 02/12/2015.

AGRA M.F, FRANÇA P.F, BARBOSA-FILHO J.M, Synopsis of the plants known as medicinal and poisonous in Northeast of Brazil. Rev Bras Farmacogn 17: 114- 140, 2007.

ALMEIDA J.N, DOS SANTOS G.R., BETETO F.M, DE MEDEIROS L.G, OBA A, SHIMOKOMAKI M, SOARES A.L. Suplementação de selênio quelatado na ração e qualidade da carne de frango. Semina: Ciências Agrárias, 33(6Supl2), 3117-3122, 2013.

ALMEIDA MELO, E., MACIEL, M. I. S., DE LIMA, V. L. A. G., \& DO NASCIMENTO, R. J. Capacidade antioxidante de frutas. Brazilian Journal of Pharmaceutical Sciences, 44(2), 2008 .

AMARAL F.M.M, RIBEIRO M.N.S, BARBOSA-FILHO J.M, REIS A.S, NASCIMENTO F.R.F, MACEDO R.O, Plants and chemical constituents with giardicidal activity. Rev Bras Farmacogn 16 (Supl.): 696-720, 2006.

AMAROWICZ R, PEGG R, RAHIMIMOGHADDAM P, BARL B, WEIL J. Free radicaL scavenging capacity and antioxidant activity of selected plant species from the Canadian prairies. Food Chem : 84:551-562, 2004

ANGELO, PRISCILA M, NEUZA J. "Compostos fenólicos em alimentos-uma breve revisão." Revista do Instituto Adolfo Lutz (Impresso) 66.1: 01-09, 2007. 
ANVISA- Resolução da Diretoria Colegiada - RDC n. 45, de 03 de novembro de 2010 acessado em: http://portal.anvisa.gov.br/ no dia 05/04/2015

ANVISA-Resolução CISA/MA/MS $\mathrm{n}^{\circ}$ 10, de 31 de julho de 1984 acessado em: http://portal.anvisa.gov.br/ no dia 04/12/2015

ARAUJO, M. A. J. Quimica dos Alimentos:Teoria e Prática. 4,ed. Viçosa:Editora UFV, 596p, 2008.

ARAÚJO, K. L., MAGNANI, M., NASCIMENTO, J. A., SOUZA, A. L., EPAMINONDAS, P. S., SOUZA, A. L., ... \& SOUZA, A. G. Antioxidant Activity of Co-Products from Guava, Mango and Barbados Cherry Produced in the Brazilian Northeast. Molecules, 19(3), 3110-3119, 2014.

AOAC-ASSOCIATION OF OFICIAL ANALYTICAL CHEMISTS. Official Methods of Analysis. 15 ed. Arlington: AOAC International, 771p, 1990.

AOAC-ASSOCIATION OF OFICIAL ANALYTICAL CHEMISTS. Official Methods of Analysis. 16 ed. Arlington: AOAC International, 1025p, 1995.

BAILEY, A. E.; Bailey's Industrial Oil and Fat Products, 5th ed., John Wiley: New York, vol. 3, 1996

BENZAQUEN, T. "Dossiê antioxidantes: os antioxidantes." Food Ingredientes Brasil 6: 16-30, 2009.

BERGER, K. G.; HAMILTON, R. J. Developments in Oils and Fats; Hamilton, R. J., ed.; Chapman \& Hall: London, cap. 7, 1995.

BRAVO L. Polyphenols: chemistry, dietary sources, metabolism and nutriotion significance. Nutr Rev ; 56 (11): 317-33, 1998. 
CANTOR A.H, DECKER E.A, COLLINS V.P. Fatty acids in poultry and egg products. In: Chow CK, editor. Fatty acidsin foods and their health implications 3rd ed. Boca Raton: CRC Press; 2008. Disponível em http://www.crcnetbase.com/ acessado em 18.04.2015

CARVALHO, P.R. Aditivos dos alimentos. Revista LOGOS, n. 12, 2005

CESTARI, L. A., GAIOTTO, R. C., ANTIGO, J. L., SCAPIM, M. R. S., MADRONA, G. S., YAMASHITA, F, PRADO, I. N. Effect of active packaging on low-sodium restructured chicken steaks. Journal of Food Science and Technology, 52(6), 3376-3382, 2014.

CHOE, E.; MIN, D. B. Mechanisms of Antioxidants in the Oxidation of Foods. Food Science and Food Safety, v. 08, p. 345-358, 2009.

DEVATKAL S.K \& NAVEEN B.M. Effect of salt and pomegranate fruit by product poweders on colour and oxidative stability of raw ground goat meat during refrigerated storege. Meat Science, 85, 306-311, 2010.

ESCRIG AJ, RINCON M, PULIDO R, SAURA-CALIXTO F. Guava fruit (P. guajava L.) as a new source of antioxidante dietary fi ber. J Agric Food Chem 49: 5489-5493, 2001.

FASOLA T.R, OLOYEDE G.K, APONJOLOSUN B.S. Chemical composition, toxicity and antioxidant activities of essential oils of stem bark of Nigerian species of Guava (Psidium guajava Linn.). EXCLI J ;10:34-43, 2011.

GOVARIS A, SOLOMAKOS N, PEXARA A, CHATZOPOULOU P.S. The antimicrobial effect of oregano essential oil, nisin and their combination against Salmonella Enteritidis in minced sheep meat during refrigerated storage. International Journal of Food Microbiology, 137(2), 175-180, 2010.

FDA,US.Food and Drug Administration. Disponível em http://www.fda.gov/ acessado em 20.04.2015

FNP, FNP Informa Economics. "Agrianual 2014: anuario da agricultura brasileira." São Paulo, 2010. 
FREITAS, E. R., BORGES, A. D. S., TREVISAN, M. T. S., WATANABE, P. H., CUNHA, A. D., PEREIRA, A. L. F. NASCIMENTO, G. D.Extratos etanóli cos da manga como antioxidantes para frangos de corte. Pesquisa Agropecuária Brasileira, 47(8), 1025-1030, 2012.

FUKUMOTO, L. R.; MAZZA, G. Assessing Antioxidant and Prooxidant Activities of Phenolic Compounds. Journal of Agriculture and Food Chemistry, v. 48, p. 3597-3604, 2000.

GARDINI, C.H.C. Efeito da vitamina $\mathbf{E}$ na qualidade da carne de frango de corte. Revista Nacional da Carne.n.288, p.97, 2001.

GOMES, A. H., DA SILVA, E. N., DO NASCIMENTO, M. R. L., \& FUKUMA, H. T. Evaluation of the 2-thiobarbituric acid method for the measurement of lipid oxidation in mechanically deboned gamma irradiated chicken meat. Food Chemistry, 80(3), 433-437, 2003.

GONDIM A.N.S, OLIVEIRA V.R, SILVA L.R, SILVA B.A, CONDEGARCIA E.A. Complete atrioventricular block on isolated guinea pig heart induced by an aqueous fraction obtained from Psidium guajava L. leaf. Rev Bras Farmacogn 16: 312-316, 2006.

GOVARIS A., SOLOMAKOS N., PEXARA A., CHATZOPOULOU P.S. The antimicrobial effect of oregano essential oil, nisin and their combination against Salmonella Enteritidis in minced sheep meat during refrigerated storage. International Journal of Food Microbiology, 137(2), 175-180, 2010

GRAU, A., GUARDIOLA, F., BOATELLA, J., BARROETA, A., \& CODONY, R. Measurement of 2-thiobarbituric acid values in dark chicken meat through derivative spectrophotometry: influence of various parameters. Journal of agricultural and food chemistry, 48(4), 1155-1159, 2000.

HAMILTON, R.J, KALU C, PRISK E, PADLE F.B, PIERCE H. Chemistry of free radicals in lipids. FOOD CHEMISTRY,v.60,n2,p.193-199,1997. 
HARBORNE J.B, BAXTER H, MOSS G.P. Phytochemical dictionary: handbook of bioactive compounds from plants. 2nd ed. London: Taylor \& Francis; 1999.

IBGE. Indicadores IBGE primeiro trimestre 2015. Disponível em: www.ibge.gov.br/.../indicadores. Acessado em: 11/09/2015

IMEH U, KHOKBAR S. Distribution of conjugated and free phenols in fruits: Antioxidant activity and cultivar variations. Journal of Agricultural and Food Chemistry, v. 50, n. 22, p. 6301-6306, 2002.

IQBAL M., CAWTHON D., BEERS K., WIDEMAN R.F., BOTJE W.G. Antioxidant Enzyme Activities and Mitochondrial Fatty Acids in Pulmonary Hypertension Syndrome (PHS) in Broilers. Poultry Science, v. 81, p. 252-260, 2002.

JOSEPH, S., CHATLI, M. K., BISWAS, A. K., \& SAHOO, J. Efficacy of pink guava pulp as an antioxidant in raw pork emulsion. Journal of food science and technology, 51(8), 1492-1500, 2014.

Kozarski, M.S.; Klaus, A.S.; Niksic, M.P.; van Griensven, L.J.L.D.; Vrvic, M.M.; Jakovljevic, D.M. Polysaccharides of higher fungi: Biological role, structure and antioxidative activity. Chem. Ind. 2014, 68, 305-320

KYNGMI M.S, EBELER E. Flavonoid effects on DNA oxidation at low concentrations relevant to physiological levels. Food Chem Toxicol; 46:96-104, 2008

LEE, S.J, UMANO K, SHIBAMOTO T, LEE K.G. Identification of volatile components in basil (Ocimum basilicum) and thyme leaves (Thymes vulgaris L.) and their antioxidant properties. Food Chemistry, v. 91, p. 131-137, 2005.

LOZOYA X, REYES-MORALES H, CHÁVEZ-SOTO M.A, MARTÍNEZGARCÍA M.C, SOTO-GONZÁLEZ Y, DOUBOVA S.V. Intestinal anti-spasmodic effect of a phytodrug of Psidium guajava folia in the treatment of acute diarrheic disease. $J$ Ethnopharmacol 83: 19-24, 2002. 
MADSEN H.L., SORENSEN B., SKIBSTED L.H., BERTELSEN G. The antioxidative activity of summer savory (Satureja hortensis L.) and rosemary (Rosmarinus officinalis L.) in dressing stored exposed to light or in darkness. Food Chemistry, 63: 173-180, 1998.

MARIUTTI, L.R.B \& BRAGAGNOLO, N. A oxidação lipídica em carne de frango e o impacto da adição de sálvia (Salvia officinalis, L.)e de alho (Allium sativum, L.) como an tioxidantes naturais; Rev. Inst. Adolfo Lutz (Impr.) v.68 n.1 São Paulo abr, 2009.

MELO A.E., MACIEL M I S.,DE LIMA, V L A.G \& DO NASCIMENTO, R.J. Capacidade antioxidante de frutas. Brazilian Journal of Pharmaceutical Sciences, 44(2), 2008.

MENSOR L L., MENEZES F.S, LEITÃO G.G, REIS A.S, SANTOS T.C.D., COUBE, C.S \& LEITÃO S. G. Screening of Brazilian plant extracts for antioxidant activity by the use of DPPH free radical method. Phytotherapy research, 15(2), 127-130, 2001.

MERCADANTE, A. Z., STECK, A., \& PFANDER, H. Carotenoids from Guava (Psidium g uajava L.): Isolation and Structure Elucidation. Journal of Agricultural and Food Chemistry, 47(1), 145-151, 1999.

MIEAN, KOO HUI \& SUHAILA MOHAMED. "Flavonoid (myricetin, quercetin, kaempferol, luteolin, and apigenin) content of edible tropical plants." Journal of agricultural and food chemistry 49.6 : 3106-3112, 2001.

MISRA, K \& T.R. SESHADRI. "Chemical components of the fruits of Psidium guava." Phytochemistry 7.4: 641-645, 1968

NACZK, MARIAN, \& FEREIDOON SHAHIDI. "Extraction and analysis of phenolics in food." Journal of chromatography A 1054.1: 95-111, 2004

NAMIKI M. Antioxidants/antimutangens in food. Crit Ver Food Sci Nutr;29(4):273-300, 1990. 
NEPA - NÚCLEO DE ESTUDOS E PESQUISAS EM ALIMENTAÇÃO. Tabela Brasileira de Composição de Alimentos (TACO). 4ed. Editora UNICAMP: Campinas, SP. p. 16-104, 2011.

NORHIDAYAH A.A, NORIHAM M, RUSOP. "The potential of nanotechnology application in improving bioactivity of Malaysian plants." Current Issues in Hospitality and Tourism: Research and Innovations: 253, 2012.

OLIVEIRA, F. Q., GOBIRA, B., GUIMARÃES, C., BATISTA, J., BARRETO, M., \& SOUZA, M. Plants species indicated in odontology. Revista Brasileira de Farmacognosia, 17(3), 466-476, 2007.

PIMENTEL C.V.M.B, FRANCKI V.M, GOLLÜCKE A.P.B. Alimentos funcionais: introdução às principais substâncias bioativas em alimentos. São Paulo: Varela; 2005.

PODSEDEK A. Natural antioxidants capacity of brassica vegetables: a review. J Food Compos Anal; 40:1-11, 2007.

POLl, H., BENNO, A., KIST, B., SANTOS, C., CARVALHO, C., REETZ, E., \& BELING, R. Anuário brasileiro da fruticultura 2011. Santa Cruz do Sul: Editora Gazeta Santa Cruz, 128,2011

RAMALHO V.C, \& JORGE N. Antioxidantes utilizados em óleos, gorduras e alimentos gordurosos. Química Nova, 29(4), 755, 2006.

RAMARATHNAM N, OSAWA T, OCHIH,KAWAKISHI S, The contribution of plant food antioxidant to humans health. Trends Food Sci Nutr; 6 (3): 75-82, 1995.

RACANICCI A.M.C, BENTE D, LEIF H.S. "Mate (Ilex paraguariensis) as a source of water extractable antioxidant for use in chicken meat." European Food Research and Technology 227.1: 255-260, 2008.

REGITANO-D’ARCE M.A.B. Deterioração de lipídeos. Fundamentos de ciência e tecnologia de alimentos. Barueri: Manole. Cap. 6, p. 243-299, 2006. 
ROCKENBACH, I. I., SILVA, G. L. D., RODRIGUES, E., GONZAGA, L. V., \& FETT, R. Atividade antioxidante de extratos de bagaço de uva das variedades Regente e Pinot Noir (Vitis vinifera). Revista do Instituto Adolfo Lutz,(Impresso), 66(2), 158-163, 2007.

ROESLER, R., MALTA, L. G., CARRASCO, L. C., HOLANDA, R. B., SOUSA, C. A. S., \& PASTORE, G. M. Atividade antioxidante de frutas do cerrado. Ciência e Tecnologia de Alimentos, 27(1), 53-60, 2007.

SELANI, M. M. Extrato de bagaço de uva como antioxidante natural em carne de frango processada e armazenada sob congelamento. Dissertação de Mestrado, Universidade de São Paulo, 2010.

SELANI M.M, CONTRERAS-CASTILLO C.J, SHIRAHIGUE L.D, GALLO C.R, PLATAOVIEDO M, MONTES-VILLANUEVA N.D. Wine industry residues extracts as natural antioxidants in raw and cooked chicken meat during frozen storage. Meat science, $88(3)$, 397-403, 2011.

SHAHIDI, FEREIDOON, MARIAN N. Food phenolics. Technomic Pub. Co., 1995.

SHAMSUDIN R, MOHAMED I.O, YAMAN N.K.M.. Thermophysical properties of Thai seedless guava juice as affected by temperature and concentration. J. Food Eng., v.66, p.395-399, 2005.

SILVA F.A, BORGES M.F.M, FERREIRA M.A. Métodos para avaliação do grau de oxidação lipídica e da capacidade antioxidante. Química Nova, 22(1), 94-103, 1999.

SINGH R.P.J, CHIDAMBAR, MURTHY K.N, JAVAPRAKASHA G.K. Studies on antioxidant activity of pomegranate (Punica granatum) peel and seed extracts using in vitro models. J. Agric. Food Chem., v. 50, n. 1, p. 81-86, 2002.

SINGLETON, VERNON L, RUDOLF ORTHOFER, ROSA M. L. Analysis of total phenols and other oxidation substrates and antioxidants by means of folin-ciocalteu reagent." Methods in enzymology 299C: 152-178, 1999. 
SOARES, S. E. Ácidos fenólicos como antioxidantes. Rev. Nutr, 15(1), 71-81,2002.

SOUSA, M. S. B., VIEIRA, L. M., SILVA, M. D. J. M. D., \& LIMA, A. D. (2011). Nutritional characterization and antioxidant compounds in pulp residues of tropical fruits. Ciência e Agrotecnologia, 35(3), 554-559, 2011

SOUSA, E. C., DE LIMA, A., DE LIMA, R. M. T., FREITAS, P. A. P., DE SOUSA, M. A. M., DE AlbuQUeRQue THOMAZ, J. C., \& CARIOCA, J. O. B. Elaboração e aceitabilidade de produtos de panificação enriquecidos com semente de goiaba (psidium guajava l.) em pó. HOLOS, 5, 199-210, 2014.

TAKAHASHI O \& HIRAGA K. Dose-response study of hemorrhagic death by dietary butylated hydroxy toluene (BHT) in male rats. Toxicol. Appl. Pharmacol., New York, 43:399-406, 1978.

TOLEDO M.C.F, ESTEVES W, HARTMANN E.M. Ciênc. Tecnol. Aliment.: 5,1, 1998

TÔRRES A.R, OLIVEIRA R.A.G, DINIZ M.F.F.M, ARAÚJO E.C. Estudo sobre o uso de plantas medicinais em crianças hospitalizadas da cidade de João Pessoa: riscos e benefícios. Rev Bras Farmacogn 15: 373-380, 2005.

TRAESEL C.K, LOPES S.T.D.A, WOLKMER P, SCHIMIDT C, SANTURIO J.M, ALVES S.H. Óleos essenciais como substituintes deantibióticos promotores de crescimento em frangos de corte: perfil de soroproteínas e peroxidação lipídica. Ciência Rural, Santa Maria, v. 41, n.2, p. 278-284, 2011.

UCHÔA, A., SILVA, A. S., SOUSA, E. C., LIMA, R. M., LIMA, A. D., \& CARIOCA, J. O. Desenvolvimento de bolo doce elaborado com farinha de resíduos obtidos do processamento de polpa de goiaba (psidium guajava, 1.). Nutrire, 36(Suplemento), 61-61, 2011.

VELASCO,J. Aplicación de antioxidants naurales em produtos cárnicos.Carnectec,v.12,n.1,p.35-37,2005. 
VENDRUSCOLO G.S, RATES S.M.K, MENTZ L.A. Dados químicos e farmacológicos sobre as plantas utilizadas como medicinais pela comunidade do bairro Ponta Grossa, Porto Alegre, Rio Grande do Sul. Rev Bras Farmacogn 15: 361-372. 2005.

VERMA A.K., RAJKUMAR V, BANERJEE R., BISWAS S, DAS A.K. Guava (Psidium guajava L.) powder as an antioxidant dietary fibre in sheep meat nuggets. AsianAustralasian journal of animal sciences, 26(6), 886, 2013.

VIEIRA L.M, SOUSA M.S.B, MANCINI-FILHO J.O.R.G.E, LIMA, A.. Fenólicos totais e capacidade antioxidante in vitro de polpas de frutos tropicais. Revista Brasileira de Fruticultura, Jaboticabal, 33(3), 888-897, 2011

WETTASINGHE M., SHAHIDI F. Evening primrose meal: a source of natural antioxidants and scavenger of hydrogen peroxide and oxygen-derived free radicals. J. Agric. Food Chem., Washington, v.47, p.1801-1812, 1999.

WITSCHI H. \& LOCK S. Toxicity of butylated hydroxy toluene in mouse following oral administration. Toxicology, Shannon, 9:137-46, 1978.

WU X, BEECHER G.R, HOLDEN J.M., HAYTOWTTZ D.B, GEBHARDT S.E, PRIOR R.L. Lipophilic and hydrophilic antioxidant capacities of common foods in the United States. J. Agric. Food Chem., Washington, v.52, n.12, p.4026-4037, 2004.

YANISHLIEVA, N. V., \& MARINOVA, E. M. (2001). Stabilisation of edible oils with natural antioxidants. European Journal of Lipid Science and Technology,103(11), 752-767, 2001.

YEUM K.J, BERETTA G, KRINSKY N.I, RUSSELL R.M, ALDINI G. Synergistic interactions of antioxidant nutrients in a biological model system.Nutrition, 25(7), 839846, 2009. 


\section{CAPÍTULO 3}

USO DO EXTRATO DE GOIABA (Psidium guajava L.) NA PROTEÇÃO DA CARNE

DE SOBRECOXA DE FRANGO SOB RESFRIGERAÇÃO E CONGELAMENTO 


\section{RESUMO}

O objetivo desse estudo foi avaliar o potencial antioxidante do extrato de goiaba na conservação de almôndegas de sobrecoxa de frango armazenadas em resfriamento e congelamento, em comparação com o antioxidante sintético. $\mathrm{O}$ extrato de goiaba (EG) foi avaliado quanto a composição fenólica total e a capacidade antioxidante in vitro (DPPH) em diferentes solventes e in vivo utilizando um modelo aplicado a almôndegas de carne de frango armazenada sob refrigeração e congelamento. A composição fenólica média obtida para o extrato de goiaba foi de 52,22 $\mathrm{mg}$ GAE/g e a capacidade antioxidante in vitro foi de $80 \%$ em relação à solução referência e utilizando água como solvente. Para o acompanhamento da oxidação lipídica da sobrecoxa de frango foram feitas almôndegas $(30 \mathrm{~g} \pm 0,5 \mathrm{~g})$ adicionadas de $0,5 \%$ de sal e divididas em 5 tratamentos com adição de antioxidantes na carne da sobrecoxa: CONT (sem adição de antioxidantes); 0,5EG (0,5\% de EG); 1,0EG (1,0\% de EG); 1,5EG (1,5\% de EG); BHT $(0,2 \%$ de BHT). Duas almôndegas por tratamento foram submetidas a análises de TBARS (Thiobarbituric Acid Reactive Substances) em duplicata a cada 2 dias para as amostras armazenadas sob resfriamento $\left(4^{\circ} \mathrm{C}\right.$ por 8 dias $)$ ou mensalmente para as amostras armazenadas sob congelamento $\left(-12^{\circ} \mathrm{C}\right.$ por 4 meses) para determinar o acúmulo de compostos de ranço durante o armazenamento. Os resultados foram analisados utilizando o teste de TUKEY para a comparação das médias, com nível de significância de 5\%, e foi feita análise de regressão comparando o tratamento CONT e os tratamentos com níveis crescentes de EG, utilizando o Mixed do SAS Enterprise Guide 5.1 (SAS Inc, Cary, NC,USA). A adição dos antioxidantes reduziu significativamente $(\mathrm{P}<0,05)$ a formação de compostos de ranço nas almôndegas, em comparação com as amostras CONT, e o tratamento 1,5EG reduziu significativamente $(\mathrm{P}<0.05)$ a produção de produtos secundários da oxidação lipídica no armazenamento resfriado, superando o BHT. No ensaio congelado, os tratamentos 1,0EG, 1,5EG e BHT não diferiram entre si $(\mathrm{P}>0,05)$, tendo a mesma capacidade antioxidante na preservação das almôndegas. Assim, o extrato de goiaba se mostrou um antioxidante natural eficiente, possível de ser utilizado em substituição ao antioxidante sintético.

Palavras-Chave: extrato natural, oxidação, carne de sobrecoxa, fruta, rancificação 


\begin{abstract}
The purpose of this study was to evaluate the antioxidant potential of guava extract (EG) for the preservation of chicken thigh meatballs stored chilled and frozen compared to the use of synthetic antioxidant. The guava extract was quantified for total phenolic composition and the antioxidant capacity in vitro (DPPH) in different solvents and in vivo using chicken meat balls stored chilled and frozen. The average of phenolic composition was $52.22 \mathrm{mg} \mathrm{GAE} / \mathrm{g}$ and the antioxidant capacity in vitro was $80 \%$ compared to the reference solution and using water as solvent. To evaluate the progression of lipid oxidation in chicken thigh meat, pre-cooked meatballs were produced $(30 \mathrm{~g} \pm 0.5 \mathrm{~g}$ ) with $0.5 \%$ of food-grade salt and distributed in 5 treatments : CONT (no antioxidants added); 0.5EG (0.5\% EG); 1.0EG (1.0\% EG); 1.5EG (1.5\% EG); BHT (0.2\% BHT). Two meatballs per treatment were analysed for TBARS (Thiobarbituric Acid Reactive Substances) concentration in duplicate each 2 days for chilled storage $\left(4{ }^{\circ} \mathrm{C}\right.$ for 8 days) or monthly for frozen storage $\left(-12{ }^{\circ} \mathrm{C}\right.$ for 4 months) to evaluate the effect os antioxidants on the oxidative stability of lipids during the storage period. The averages were compared using the Tukey test with 5\% significance level and regression analysis was performed to compare CONT with treatments with increasing levels of EG using the Mixed SAS Enterprise Guide 5.1 (SAS Inc., Cary, NC, USA). The addition of natural or synthetic antioxidants significantly reduced $(\mathrm{P}<0.05)$ the formation of rancid compounds in chicken meat balls stored chilled, compared with CONT, and 1.5EG treatment showed the lowest $(\mathrm{p}<0.05)$ TBARS values. In frozen storage, 1.0EG, 1.5EG and BHT protected equally $(\mathrm{p}<0.05)$ lipids from oxidation compared to CONT at the end of 4 months of storage. In conclusion, guava extract showed a antioxidant effect and can be used to replace synthetic antioxidants in thigh meat products.
\end{abstract}

Keywords: natural extract, oxidation, thigh, Psidium guajava, TBARS 


\section{INTRODUÇÃO}

A carne de frango é responsável por $57 \%$ da produção nacional de carnes, sendo que $32,26 \%$ dos abates se concentram no Paraná, e 67,7\% da produção é destinada ao mercado interno (ABPA., 2014). Só no primeiro trimestre de 2015 foram abatidas 1,380 bilhão de cabeças de frangos, sendo acumulados 3,162 milhões de toneladas, segundo indicadores do IBGE (2015).

A sobrecoxa de frango é considerada uma carne com alta concentração de lipídios, de acordo com Hautrive et al. (2012), que comparou carne de coxa e sobrecoxa com pernil suíno, alcatra e filé de avestruz. A carne da sobrecoxa contém a maior quantidade de lipídios sendo seguida da alcatra, e também foi a carne com maior quantidade de ácidos graxos insaturados com $42,6 \%$, seguido da carne suína com $20,26 \%$. Sabendo que as carnes com predominância de ácidos graxos insaturados são altamente susceptíveis a oxidação lipídica (Almeida et al., 2013), é necessário encontrar formas de aumentar o tempo de prateleira da carne de sobrecoxa em armazenamento no mercado.

O uso de antioxidantes sintéticos como BHT, BHA entre outros, é largamente utilizado pela indústria de alimentos, principalmente em carnes processadas. Porém, com descobertas sobre os riscos desses antioxidantes sintéticos a saúde do consumidor como, por exemplo, o favorecimento de hemorragias (Takahashi \& Hiraga, 1978), além da preferência dos consumidores por produtos naturais, faz-se necessária a busca constante por produtos naturais com ação antioxidante (Govaris et al., 2010).

O extrato de goiaba é rico em compostos antioxidantes como taninos, flavonóides, óleos essenciais, álcoois sesquiterpenóides e ácidos triterpenóides (Gondim et al., 2006; Amaral et al., 2006). Além dessa fruta ser produzida em grandes quantidades no Brasil, sendo produzidas 316.301 toneladas em 2014 (Agrianual, 2014).

Assim, o objetivo desse experimento foi avaliar a capacidade antioxidante do extrato da goiaba como antioxidante natural na conservação de almôndegas de sobrecoxa de frango em refrigeração e congelamento em comparação com o uso de um antioxidante sintético. 


\section{MATERIAIS E MÉTODOS}

\subsection{Caracterização do extrato de goiaba}

O extrato de Psidium guavaja L. em pó, doado pela UFG, foi obtido a partir de resíduos da fruta compostos por casca, poupa e sementes provenientes da indústria de fabricação de doces. Inicialmente foi efetuada a secagem do resíduo úmido em estufa ventilada a temperatura de $40^{\circ} \mathrm{C}$ por três dias. Depois, o resíduo seco foi moído em moinho tipo faca obtendo-se o extrato em pó, que foi usado neste projeto.

As análises para caracterização da composição fenólica total e da atividade antioxidante in vitro do extrato foram efetuadas no Laboratório de Nutrição Animal da FAV/UnB (Universidade de Brasília) localizado na Fazenda Água Limpa, conforme descrito a seguir.

\subsection{Fenólicos Totais}

Para a determinação da composição em fenólicos totais foi utilizado o método espectrofotométrico de Folin-Ciocalteau descrito por Singleton et al. (1999), utilizando ácido gálico como padrão. $\mathrm{O}$ extrato de goiaba foi diluído em água destilada, etanol e acetona $(0,5$ $\mathrm{ml}$, com três repetições), com a finalidade de determinar o melhor meio de extração, depois as diluições obtidas foram misturados em 2,5 mL de Folin-Reagente de Ciocalteu (Merck 9001, Darmstadt, Alemanha). Após três segundos, 7,5 ml de solução de carbonato de sódio a $20 \%$ foi adicionado e a solução foi misturada e diluída com água em um volume final de $50 \mathrm{~mL}$. Após duas horas no escuro, as absorvências das amostras foram medidas a $765 \mathrm{~nm}$ usando um espectrofotômetro da marca GEHAKA (modelo UV-340G).

A curva padrão foi construída utilizando o ácido gálico nas concentrações de $10 \mu \mathrm{g} / \mathrm{ml}$ a $500 \mu \mathrm{g} / \mathrm{ml}$. O conteúdo total de fenólico foi expresso em $\mathrm{mg}$ de equivalente de ácido gálico por grama de extrato adicionado (mg GAE/g). 


\subsection{DPPH}

O extrato liofilizado de goiaba foi colocado em tubo erlenmeyer de $50 \mathrm{ml}$ na proporção de $1 \mathrm{~g} / 50 \mathrm{ml}$ (água destilada, etanol ou acetona), tampados e colocados em mesa agitadora ETHICHNOLOGY durante 40 minutos a velocidade $140 \mathrm{rpm}$. Antes do início das determinações, o material passou por filtragem em papel de filtro comum para retirada do precipitado.

Para determinação da atividade sequestrante de radicais livres do extrato nos diferentes meios de extração, foi utilizado o potencial de inibição da oxidação com uso do radical 2,2-difenil-1-picrilidrazil (DPPH) pelo método de Mensor et al. (2001), em que a atividade anti-radical é determinada na forma de \% de inibição (PI) calculada através da taxa de declínio da absorbância da solução de DPPH dos extratos e padrões após 45 minutos de reação em relação à solução referência (DPPH em etanol) de acordo com a fórmula:

AA\% (atividade antioxidante) ou capacidade de sequestro (scavenging):

$\mathrm{AA}(\%)=100-\{[(\mathrm{AA}-\mathrm{AB}) \mathrm{x} 100] / \mathrm{AC}\}$

\subsection{Preparo e armazenamento das almôndegas de sobrecoxa de frango}

No dia 30/09/2014 foram adquiridos 7,0 kg de sobrecoxa de frango refrigerada, desossado e sem pele e com data de fabricação do dia 30/09/2014 em supermercado na cidade de Brasília/DF, e transportados ao Laboratório de Nutrição Animal (LNA/UNB). A carne foi moída em processador de alimentos e adicionada de $0,5 \%$ de $\mathrm{NaCl}$ (sal de cozinha), após homogeneização foi dividida em $5 \mathrm{sub}$-amostras de $1,2 \mathrm{~kg}$, sendo que o excedente embalado a vácuo e congelado para posterior análise bromatológica. As 5 amostras foram divididas em tratamentos e homogeneizadas extrato de goiaba em pó e BHT, segundo os tratamentos:

- CONT: sem adição de antioxidantes (controle negativo)

- BHT: adição de $0,2 \%$ do antioxidante sintético BHT (controle positivo)

- 0,5 : adição de $1,5 \%$ de extrato em pó de goiaba (EG)

- 1,0: adição de 1,0\% de extrato em pó de goiaba (EG) 
- 1,5: adição de 0,5\% de extrato em pó de goiaba (EG)

Após completa homogeneização, foram feitas almôndegas de $30 \mathrm{~g}$ (+- 0,5 g) cada, que foram embaladas a vácuo e pré-cozidas em banho-maria a $100{ }^{\circ} \mathrm{C}$ por 10 min e resfriadas em água com gelo. Após resfriamento, foram separadas 10 almôndegas de cada tratamento, que foram re-embaladas em sacos plásticos permeáveis ao oxigênio devidamente identificados, duas amostras por embalagem e armazenadas sob refrigeração em câmara fria a $4{ }^{\circ} \mathrm{C}$ por até oito dias.

Para o estudo do armazenamento sob congelamento, a uma temperatura média de -12 ${ }^{\circ} \mathrm{C}$, mais oito almôndegas foram separadas por tratamento, embaladas em sacos plásticos permeáveis ao oxigênio, duas amostras por embalagem, devidamente identificadas, e mantidas em congelador doméstico por até 4 meses.

\subsection{Análise das amostras resfriadas}

Durante o período de armazenamento em câmara fria, foram coletadas duas amostras de cada tratamento, que foram analisadas em duplicata, com a finalidade de acompanhar a oxidação lipídica da carne usando o método de TBARS (Thiobarbituric acid reactive substances). As análises foram feitas em cinco dias correspondendo ao dia 0 (30/09/2014), ao dia $2(02 / 10 / 2014)$, ao dia $4(04 / 10 / 2014)$, ao dia $6(06 / 10 / 2014)$ e ao dia $8(08 / 10 / 2014)$ de armazenamento. Os valores médios de TBARS foram expressos em $\mu$ mol de malonaldeído por quilograma $(\mathrm{MDA} / \mathrm{kg})$ de amostra.

\subsection{Análise das amostras congeladas}

Durante o período de armazenamento sob congelamento, foram coletadas mensalmente duas amostras de cada tratamento, que foram analisadas em duplicata, com a finalidade de acompanhar a oxidação lipídica da carne com o método de TBARS (Thiobarbituric acid reactive substances). As análises no primeiro dia (30/9/2014) foram efetuadas com as almôndegas antes do congelamento (DIA 0), com um mês de armazenamento (MÊS 1, dia 29/10/2014), dois meses (MÊS 2, dia 01/12/2014), três meses (MÊS 3, dia 30/12/2014) e quatro meses de armazenamento (MÊS 4, dia 20/01/2014). Os valores médios de TBARS foram expressos em $\mu$ mol de malonaldeído (MDA) por quilograma de amostra. 


\subsection{Determinação da oxidação lipídica}

As substâncias reativas ao ácido tiobarbitúrico (TBARS) resultantes da oxidação lipídica das amostras da carne da sobrecoxa de frango, foram determinadas segundo o método de Madsen et al. (1998). Para cada almôndega foram pesadas $5 \mathrm{~g}$ (+- 0,05 g), em duplicata, em tubo tipo falcon de $50 \mathrm{ml}$ e adicionado $15 \mathrm{ml}$ de solução de tricloroacético 7,5 \% + Propil Galato $0,1 \%$ + EDTA 0,1\% e homogeneizados no misturador tipo Ultra Turax (marca IKA), sendo filtrado em seguida com o uso de papel de filtro comum.

Em tubo falcon de $15 \mathrm{ml}$ com tampa, foi pipetado $5 \mathrm{ml}$ do filtrado e adicionado de 5 $\mathrm{ml}$ de solução TBA, para a formação do composto cromóforo de cor vermelha em banhomaria durante 40 minutos $\left(100^{\circ} \mathrm{C}\right)$. Em seguida as soluções foram resfriadas em água com gelo por 15 minutos para a leitura da absorbância nos comprimentos de onda de 532 e $600 \mathrm{~nm}$ usando um espectrofotômetro da marca GEHAKA (modelo UV-340G).

\subsection{Análise Bromatológica da carne da sobrecoxa de frango}

Para a composição bromatológica foram avaliados, em quadruplicada, a umidade (UM), matéria mineral (MN), o teor de proteína bruta (PB) e o teor de lipídios totais (LPT), na carne crua da sobrecoxa.

Para o cálculo da umidade foi inicialmente obtida a matéria seca (AOAC, 1990) e, em seguida, foi determinada a umidade, através da fórmula:

$$
\text { Umidade }=100 \%-\% \text { Matéria Seca }
$$

A matéria mineral foi quantificada pelo método gravimétrico por incineração em mufla a $600^{\circ} \mathrm{C}$ por 4 horas, de acordo com a metodologia descrita por AOAC (1990). O teor de proteína bruta foi determinado pelo método de destilação e titulação ou método Kjedahl (AOAC, 1990). O teor de lipídios totais foi determinado pelo método gravimétrico utilizando solvente de éter de petróleo de acordo com metodologia de Soxhlet (AOAC, 1995). 


\subsection{Análise estatística}

O desenho experimental foi inteiramente casualizado, com um controle negativo e quatro tratamentos. Para a análise estatística foi utilizado o teste de TUKEY para a comparação das médias, com nível de significância de 5\%, e o PROC REG para análise de regressão entre o controle negativo e os tratamentos com níveis crescentes de EG utilizando o Mixed do SAS Enterprise Guide 5.1 (SAS Inc, Cary, NC,USA). 


\section{RESULTADOS E DISCUSSÃO}

\subsection{Compostos Fenólicos e Atividade anti-radical DPPH}

Como o extrato utilizado foi o mesmo, os resultados estão apresentados e discutidos no capítulo anterior (itens 3.1 e 3.2).

\subsection{Composição bromatológica da carne da sobrecoxa}

Os resultados da carne da sobrecoxa podem ser observados na Tabela 3.1. Comparando os resultados obtidos na carne de sobrecoxa usada no experimento com os dados da Tabela Brasileira de Composição de Alimentos (TACO), pode-se observar que o valor médio obtido de proteína bruta foi de $21,2 \%$ e é superior ao valor médio apresentado na tabela TACO $(17,6 \%)$. O contrário foi verificado para o teor de extrato etéreo $(6,36 \%)$, que está abaixo do valor apresentado na tabela TACO (9,6\%). Já os resultados de umidade e matéria mineral estão de acordo com a tabela (NEPA, 2011).O maior teor de proteína bruta e o menor teor de lipídios nos cortes utilizados, possivelmente são decorrentes a variações da genética das aves e do programa alimentar utilizado. De acordo com Reginatto et al., (2000), melhores deposições de proteína e gordura podem ser obtidas aplicando menores relações de energia e proteína na ração, favorecendo a formação de uma carne com mais proteína e com menos gordura. 
Tabela 3.1: Médias e desvios da composição bromatológica, em porcentagem, da carne do peito de frango sem pele adquirida em supermercado e valores fornecidos pela tabela TACO de alimentos (NEPA, 2011), $(n=4)$

\begin{tabular}{ccccc}
\hline \multicolumn{4}{c}{ COMPOSIÇÃO BROMATOLÓGICA (\%) } \\
\hline & Umidade & Matéria mineral & Proteína bruta & Extrato etéreo \\
Carne de & $73,7 \pm 1,2$ & $1,5 \pm 0,1$ & $21,2 \pm 1,5$ & $6,4 \pm 0,9$ \\
sobrecoxa & 72,7 & 1,3 & 17,6 & 9,6 \\
TACO & 7,7 &
\end{tabular}

\subsection{Ensaio de armazenamento refrigerado}

O Gráfico 3.1 mostra os valores médios de TBARS para as amostras de sobrecoxa de frango antes e depois do cozimento em banho-maria (cruas e cozidas). O processo de cocção realizado teve ação direta $(\mathrm{p}>0,05)$ na aceleração da oxidação dos lipídios, aumentando a produção dos compostos de ranço verificados nos maiores resultados de TBARS, em comparação com as amostras cruas para os tratamentos 0,5EG, 1EG, BHT e CONT. Esse resultado já era esperado, uma vez que o aumento de temperatura desencadeia reações pró-oxidantes na carne por meio da desnaturação proteica, rompimento de membranas celulares e liberação de ferro (Rhee et al.,1998).

A adição dos extratos 1EG e 1,5 EG e do BHT foi eficiente no controle do processo de auto-oxidação, mesmo com o cozimento ocorrendo a temperaturas elevadas $\left(100{ }^{\circ} \mathrm{C}\right)$. Efeito protetor semelhante foi relatado anteriormente por Castro et al. (2011) comparando carne de frango crua e cozida com a adição de vitamina $\mathrm{E}$ e produto à base de urucum, obtendo resultados menores de oxidação na carne cozida adicionada dos antioxidantes. 


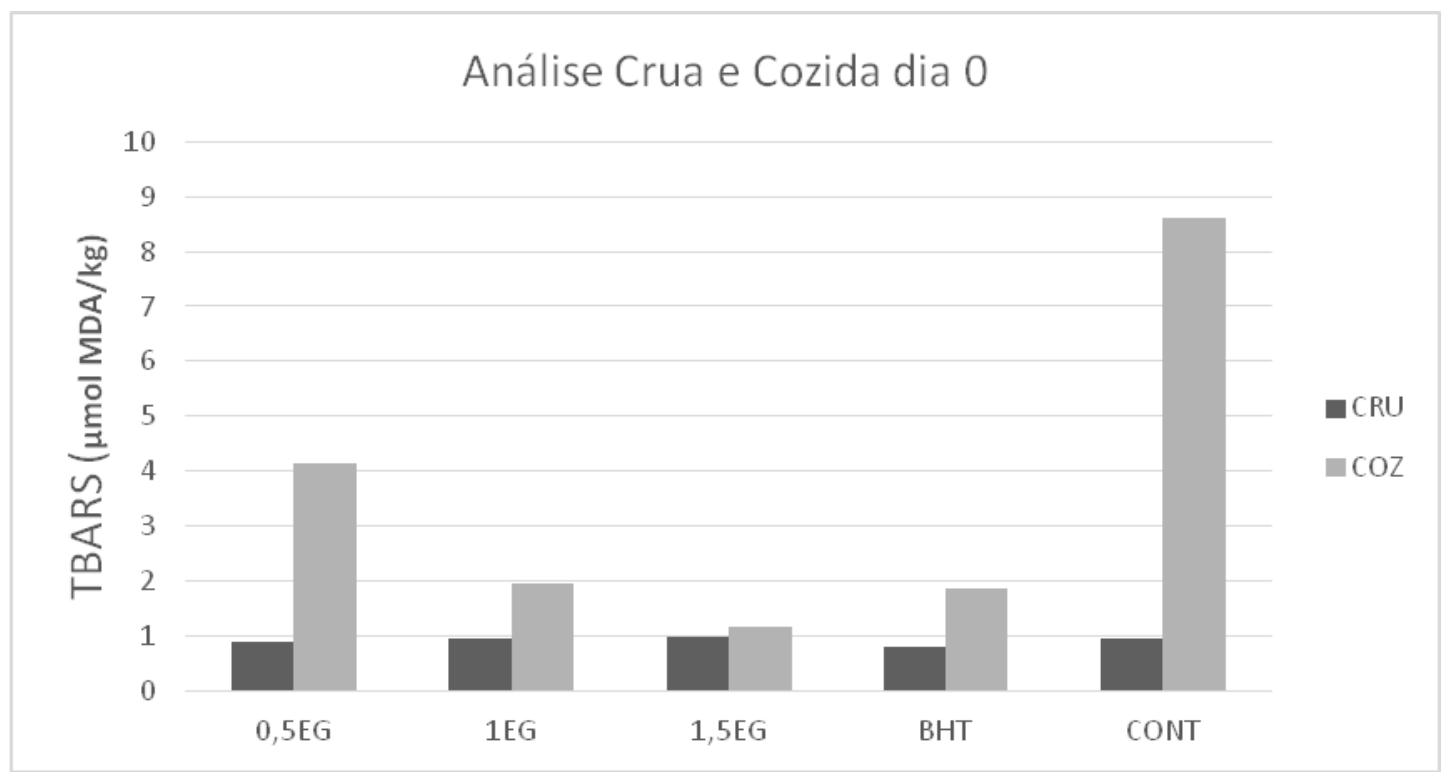

Gráfico 3.1: Análise de TBARS das almondegas de frango antes e após o cozimento ( $n=4)$

Os resultados médios de TBARS obtidos para as amostras cozidas e armazenadas sob refrigeração podem ser observados na Tabela 3.2 e no Gráfico 3.2. Observa-se que no dia 0 as almôndegas contendo 1,0 e 1,5\% de extrato de goiaba ou com BHT já apresentam menor produção de compostos de ranço, quando comparados ao CONT e a adição de $0,5 \%$ extrato de goiaba $(\mathrm{p}<0,05)$. No segundo dia de armazenamento, todos os tratamentos apresentaram menores valores de oxidação do que o CONT, sendo que o tratamento $0,5 \mathrm{EG}$ foi tão eficaz quanto o tratamento com antioxidante sintético BHT, e os tratamentos 1,0EG e 1,5EG não diferiram entre si.

Já a partir do dia 4 de armazenamento, o tratamento contendo a maior dosagem de extrato de goiaba $(1,5 \mathrm{EG})$ passou a ser o tratamento com menor produção de compostos de ranço $(\mathrm{p}<0,05)$, ou seja, que melhor preservou a carne da oxidação, sendo seguido do 1,0EG e do BHT. Apesar de diferir estatisticamente $(\mathrm{p}<0,05)$ do CONT a partir do dia 4, o tratamento contendo $0,5 \mathrm{EG}$, não foi capaz de superar o efeito do antioxidante sintético BHT ou das demais concentrações do EG. 
Tabela 3.2- Valores médios de TBARS ( $\mu$ mol MDA/kg de carne) em almôndegas de carne de sobrecoxa de frango, pré-cozidas e armazenadas por até 8 dias a $4^{\circ} \mathrm{C}(\mathrm{n}=4)$

TEMPO DE ARMAZENAMENTO (dias)

\begin{tabular}{cccccc}
\hline & \multicolumn{1}{c}{$0^{1}$} & \multicolumn{2}{c}{$2^{2}$} & $4^{3}$ & $8^{5}$ \\
\hline CONT & $8,62^{\mathrm{a}}$ & $43,84^{\mathrm{a}}$ & $62,75^{\mathrm{a}}$ & $82,91^{\mathrm{a}}$ & $78,18^{\mathrm{a}}$ \\
$0,5 \mathrm{EG}$ & $4,15^{\mathrm{ab}}$ & $18,53^{\mathrm{b}}$ & $52,86^{\mathrm{b}}$ & $45,04^{\mathrm{b}}$ & $45,28^{\mathrm{b}}$ \\
$1,0 \mathrm{EG}$ & $1,97^{\mathrm{b}}$ & $7,91^{\mathrm{c}}$ & $20,89^{\mathrm{c}}$ & $15,61^{\mathrm{d}}$ & $25,63^{\mathrm{d}}$ \\
$1,5 \mathrm{EG}$ & $1,17^{\mathrm{b}}$ & $2,23^{\mathrm{c}}$ & $5,45^{\mathrm{d}}$ & $3,26^{\mathrm{e}}$ & $5,60^{\mathrm{e}}$ \\
$\mathrm{BHT}$ & $1,85^{\mathrm{b}}$ & $16,67^{\mathrm{b}}$ & $24,45^{\mathrm{c}}$ & $27,07^{\mathrm{c}}$ & $37,17^{\mathrm{c}}$ \\
$\mathrm{CV}(\%)$ & 25,3 & 24,3 & 10,2 & 8,7 & 9,5 \\
P & $<0,0001$ & $<0,0001$ & $<0,0001$ & $<0,0001$ & $<0,0001$ \\
$\mathrm{R}^{2}$ & 0,39 & 0,63 & 0,58 & 0,62 & 0,74 \\
\hline
\end{tabular}

a,b,c Médias com letras diferentes na mesma coluna indicam diferença estatística significativa $(\mathrm{p}<0,05)$ Análise de regressão entre CONT e tratamentos com níveis de EG:

$y^{1}=5,51695-3,16128 x ; y^{2}=33,62982-41,22170 x ; y^{4}=59,01754-39,09791 x ; y^{5}=61,23928-36,87804 x$

O tratamento 1,5EG foi o que melhor conservou as almôndegas produzidas com a carne da sobrecoxa, seguido de 1,0EG, BHT e 0,5EG sendo que todos os tratamentos foram eficazes, em comparação com o CONT. Vale ressaltar que o uso da maior dosagem do extrato de goiaba, foi mais eficiente na proteção da carne do que o antioxidante sintético BHT, demonstrando a possibilidade do uso do extrato de goiaba em substituição ao BHT como antioxidante em produtos cárneos.

Diferente do encontrado por Adeyemi et al. (2013) e Packer et al. (2015) que utilizaram, respectivamente, extratos de sementes de frutas cítricas e de goiaba comparando com BHT, em coxa e sobrecoxa de frangos, não encontraram diferenças significativas entre os antioxidantes sintéticos e naturais utilizados.

Mesmo a carne de sobrecoxa de frango sendo mais susceptível a oxidação lipídica, por ser uma carne com alto teor de gorduras insaturadas, o extrato utilizado foi eficiente na preservação dos lipídios em todas as dosagens utilizadas. Os resultados das análises de regressão mostram que, com exceção do DIA 4, todas as equações obtidas foram lineares negativas, demonstrando que maiores dosagens de extrato levam a menor acúmulo de compostos de ranço, logo a uma maior proteção da carne. 


\section{TBARS SOBRECOXA RESFRIGERADO}

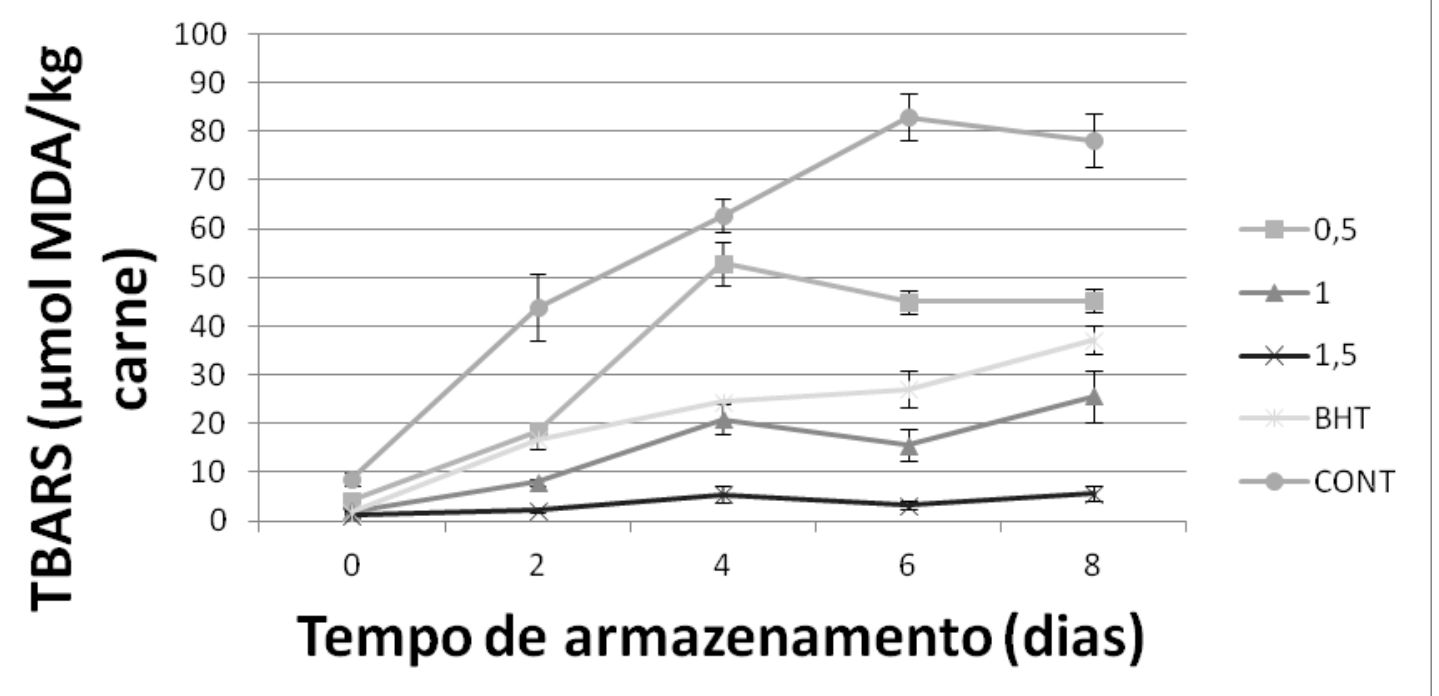

Gráfico 3.2- Valores de TBA de sobrecoxa de frango refrigerado durante 8 dias, em diferentes dosagens de extrato de goiaba, BHT

Assim, usando a equação linear com o melhor coeficiente de determinação: $\mathrm{R}=0,74$ (DIA 8); foi possível estimar a concentração ótima de EG para o valor mínimo de TBARS, ou seja, $\mathrm{Y}=0 \mu \mathrm{mol} \mathrm{MDA} / \mathrm{kg}$ de carne, sendo que $\mathrm{Y}=$ quantidade de TBARS e $\mathrm{X}=$ porcentagem de EG. $\mathrm{O}$ valor encontrado foi de 1,66\% de EG no DIA 8, ligeiramente superior ao maior valor de EG aplicado no experimento.

\subsection{Ensaio de armazenamento em congelamento}

Na Tabela 3.3 e no Gráfico 3.3 apresentam-se os valores de TBARS das almôndegas de sobrecoxa de frango armazenadas durante 4 meses de congelamento. Observa-se que já no primeiro dia de análise (dia 0), os tratamentos com extrato de goiaba e com BHT apresentaram valores de TBARS estatisticamente menores $(\mathrm{p}<0,05)$ que o CONT, sendo que 1,0EG, 1,5EG e BHT foram estatisticamente iguais ( $>00,05)$. Após um mês de armazenamento congelado, os tratamentos que melhor conservaram os lipídios da carne foram o 1,5EG e o BHT sendo que ambos apresentaram valores médios de TBARS estatisticamente semelhantes ( $p>0,05)$, seguidos do 1,0EG e 0,5EG. No mês 2, os tratamentos com $1,0 \%$ e $1,5 \%$ de extrato de goiaba se destacaram com os menores 
$(\mathrm{p}<0,05)$ valores de TBARS, seguidos de BHT e 0,5EG. Após 3 e 4 meses de armazenamento, os tratamentos 1,0EG, 1,5EG e BHT apresentaram maior efeito antioxidante $(\mathrm{p}<0,05)$ devido à menor produção de compostos de ranço e não diferiram entre si $(\mathrm{p}<0,05)$, já o 0,5EG, apesar de ter sido melhor que o CONT, apresentou resultados inferiores aos demais.

Dragoev et al. (2015) analisaram a progressão da oxidação lipídica de carne da coxa e sobrecoxa de frangos armazenada sob congelamento durante 360 dias, com uso de antioxidantes naturais compostos de alecrim (36\%) e de extrato seco da árvore japonesa Sophora japonica (52\%). Os autores relataram resultados significantemente menores para os tratamentos com antioxidante quando comparados com o controle, semelhante ao ocorrido no presente trabalho.

Apesar de não terem sido identificados individualmente neste trabalho, a capacidade antioxidante da goiaba se justifica pela presença dos componentes fenóis: ácido isovanílico, ácido vanílico, ácido hidroxidobenzóico, ácido cumárico, epicatequinas e quercetinas (Melo et al., 2011), normalmente encontrados.

Tabela 3.3- Valores médios de TBARS ( $\mu$ mol MDA/kg de carne) em almôndegas de carne de sobrecoxa pré-cozidas e congeladas por até 4 meses $(n=4)$

TEMPO DE ARMAZENAMENTO (MESES)

\begin{tabular}{cccccc}
\hline TRAT & $0^{1}$ & $1^{2}$ & $2^{3}$ & $3^{4}$ & $4^{5}$ \\
CONT & $8,62^{\mathrm{a}}$ & $12,22^{\mathrm{a}}$ & $21,88^{\mathrm{a}}$ & $20,23^{\mathrm{a}}$ & $17,59^{\mathrm{a}}$ \\
$0,5 \mathrm{EG}$ & $4,15^{\mathrm{b}}$ & $7,30^{\mathrm{b}}$ & $11,26^{\mathrm{b}}$ & $10,69^{\mathrm{b}}$ & $9,48^{\mathrm{b}}$ \\
$1,0 \mathrm{EG}$ & $1,97^{\mathrm{c}}$ & $4,18^{\mathrm{c}}$ & $3,57^{\mathrm{cd}}$ & $3,70^{\mathrm{c}}$ & $4,32^{\mathrm{c}}$ \\
$1,5 \mathrm{EG}$ & $1,18^{\mathrm{c}}$ & $1,50^{\mathrm{d}}$ & $2,04^{\mathrm{d}}$ & $2,04^{\mathrm{c}}$ & $4,47^{\mathrm{c}}$ \\
$\mathrm{BHT}$ & $1,85^{\mathrm{c}}$ & $3,71^{\mathrm{cd}}$ & $5,38^{\mathrm{c}}$ & $5,47^{\mathrm{c}}$ & $4,47^{\mathrm{c}}$ \\
$\mathrm{CV}(\%)$ & 25,3 & 17,5 & 13,9 & 24,9 & 20,7 \\
P & $<0,0001$ & $<0,0001$ & $<0,0001$ & $<0,0001$ & $<0,0001$ \\
$\mathrm{R}^{2}$ & 0,40 & 0,48 & 0,50 & 0,49 & 0,45
\end{tabular}

$\overline{\text { a,b,c }}$ Médias com letras diferentes na mesma coluna indicam diferença estatística significativa $(\mathrm{p}<0,05)$ Análise de regressão entre CONT e tratamentos com níveis de EG:

$\mathrm{Y}^{1}=5,51696-3,16132 \mathrm{x} ; \mathrm{Y}^{2}=8,70823-4,71124 \mathrm{x} ; \mathrm{Y}^{3}=14,51054-9,16573 \mathrm{x} ; \mathrm{Y}^{4}=13,68788-8,48736 \mathrm{x}$;

$\mathrm{Y}^{5}=11,83171-681071 \mathrm{x}$

No Gráfico 3.3 pode-se observar que todos os tratamentos com antioxidantes produziram valores de TBARS significativamente menores $(\mathrm{p}<0,05)$ que o CONT, sendo 
que nos meses 1 e 2 o melhor tratamento foi o 1,5EG. Ao longo de todo período de armazenamento, o tratamento $0,5 \mathrm{EG}$ foi o tratamento que apresentou os maiores $(\mathrm{p}<0,05)$ valores de TBARS em comparação com os demais níveis, sendo assim, foi a concentração de extrato de goiaba menos eficiente na preservação dos lipídios da carne, apesar de apresentar resultados significativamente menores do que o CONT. Os demais tratamentos 1,0EG, 1,5EG e BHT foram igualmente eficientes na proteção das almôndegas de sobrecoxa, o que comprova a alta capacidade de proteção do extrato de goiaba.

Utilizando extratos de uvas Isabel e Niagara, BHT e eritobarto de sódio na conservação de carne de sobrecoxas de frango armazenadas em congelamento por até 9 meses, Selani et al. (2011) observaram que todos os tratamentos foram eficazes na conservação da carne de frango. O mesmo ocorreu no presente trabalho em que todos os tratamentos com antioxidantes naturais e sintéticos foram eficazes na proteção da carne.

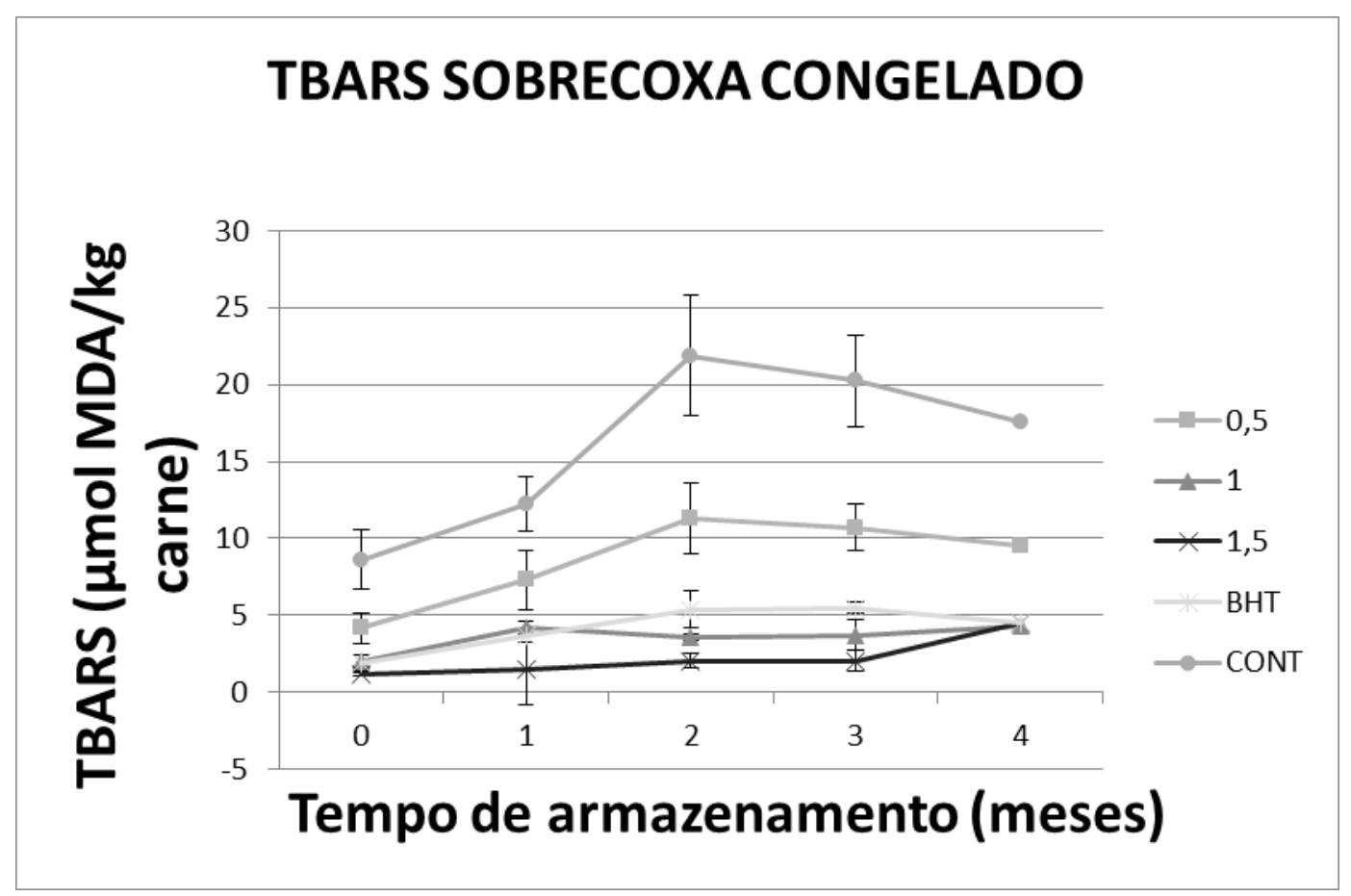

Gráfico 3.3- Valores de TBARS do peito de frango congelado durante 4 meses, em diferentes dosagens de extrato de goiaba e BHT.

A oxidação lipídica continua ocorrendo normalmente mesmo em condições de baixas temperaturas, embora numa velocidade reduzida, conforme afirmado por Gomes et al. (2003). Assim, o uso de antioxidantes pode trazer benefícios aumentando o tempo de 
prateleira desse tipo de carne, mesmo em congelamento e o extrato de goiaba se mostrou uma boa opção de antioxidante natural.

Para todos os meses avaliados quanto à formação de compostos de ranço foram encontrados efeitos lineares da adição de dosagens crescentes de extrato de goiaba nas almôndegas de carne da sobrecoxa armazenadas sob congelamento. Aplicando as equações encontradas foi possível estimar a dosagem de EG que produz o menor valor de TBARS, logo, a maior proteção antioxidante. Assim, foram usadas as equações lineares negativas com o melhor coeficiente de correlação: $\mathrm{R}^{2}=0,5$ (MÊS2); $\mathrm{R}^{2}=0,49$ (MÊS 3); $\mathrm{R}^{2}=0,45$ (MÊS 4). Sendo que $\mathrm{Y}=$ valor de TBARS (zero) e $\mathrm{X}=$ porcentagem de EG. Os valores encontrados foram de 1,58\% no MÊS 2 e 1,61\% de EG no MÊS 3 e 1,73\% no MÊS 4. 


\section{CONCLUSÃO}

O uso de extrato de goiaba preservou eficientemente os lipídios da carne da sobrecoxa de frango pré-cozida armazenada sob refrigeração e congelamento contra a oxidação lipídica, independente da concentração estudada. No entanto, para o armazenamento refrigerado a adição de 1,5\% de EG foi o tratamento mais eficiente, superando inclusive o BHT. Já nas almondegas sob congelamento, a inclusão de 1,0\% de EG parece tão eficiente quanto o BHT na proteção dos lipídios da carne. Assim, o extrato de goiaba pode ser considerado como substituto natural ao antioxidante BHT em produtos à base de carne de sobrecoxa de frango. 


\section{REFERÊNCIAS BIBLIOGRÁFICAS}

ADEYEMI, K. D., O. A. OlORUnSANYA, AND O. T. ABE. "Effect of Citrus Seed Extracts on Oxidative Stability of Raw and Cooked Chicken Meat." Iranian Journal of Applied Animal Science 3.1 (2013): 195-199, 2013.

AGRIANUAL 2014. Anuario da agricultura brasileira."FNP, FNP Informa Economics São Paulo, 2014

ALMEIDA J.N, DOS SANTOS G.R., BETETO F.M, DE MEDEIROS L.G, OBA A, SHIMOKOMAKI M, SOARES A.L. Suplementação de selênio quelatado na ração e qualidade da carne de frango. Semina: Ciências Agrárias, 33(6Supl2), 3117-3122, 2013.

AMARAL F.M.M, RIBEIRO M.N.S, BARBOSA-FILHO J.M, REIS A.S, NASCIMENTO F.R.F, MACEDO R.O. Plants and chemical constituents with giardicidal activity. Rev Bras Farmacogn 16 (Supl.): 696-720, 2006.

AOAC-ASSOCIATION OF OFICIAL ANALYTICAL CHEMISTS. Official Methods of Analysis. 15 ed. Arlington: AOAC International, 771p, 1990.

AOAC-ASSOCIATION OF OFICIAL ANALYTICAL CHEMIST. Official Methods of Analysis. 16 ed. Arlington: AOAC International, 1025p, 1995.

CASTRO W.F, MARIUTTI L.R.B, BRAGAGNOLO N. "The effects of colorifico on lipid oxidation, colour and vitamin $E$ in raw and grilled chicken patties during frozen storage." Food chemistry 124.1: 126-131, 2011. 
DRAGOEV, STEFAN GEORGIEV. "Inhibition of Lipid Oxidation of Frozen Chicken Legs by Treatment with Sodium Lactate, Natural Antioxidants and VacuumPackaging." EC Nutrition 1: 203-216, 2015.

GOMES A.H, DA SILVA E.N, DO NASCIMENTO M.R.L, FUKUMA H.T. Evaluation of the 2-thiobarbituric acid method for the measurement of lipid oxidation in mechanically deboned gamma irradiated chicken meat. Food Chemistry, 80(3), 433-437, 2003.

GONDIM A.N.S, OLIVEIRA V.R, SILVA L.R, SILVA B.A, CONDEGARCIA E.A. Complete atrioventricular block on isolated guinea pig heart induced by an aqueous fraction obtained from Psidium guajava L. leaf. Rev Bras Farmacogn 16: 312-316, 2006.

GOVARIS, A., SOlOMAKOS, N., PEXARA, A., \& CHATZOPOUlOU, P. S. (2010). The antimicrobial effect of oregano essential oil, nisin and their combination against Salmonella Enteritidis in minced sheep meat during refrigerated storage. International Journal of Food Microbiology, 137(2), 175-180, 2010.

HAUTRIVE, T. P., MARQUES, A., \& KUBOTA, E. H. Avaliação da composição centesimal, colesterol e perfil de ácidos graxos de cortes cárneos comerciais de avestruz, suíno, bovino e frango. Alimentos e Nutrição Araraquara,23(2), 327-334, 2013.

IBGE. Indicadores IBGE primeiro trimestre 2015. Disponível em: www.ibge.gov.br/.../indicadores. Acessado em: 11/09/2015

KESSLER, A.M.; SNIZEK JR.; P.N., BRUGALLI, I. Manipulação da quantidade de gordura na carcaça de frangos. In: CONFERÊNCIA APINCO 2000 DE CIÊNCIA E TECNOLOGIA AVÍCOLA, Campinas, 2000. Anais. Campinas: FACTA, 2000. p.107-133, 2000.

MADSEN H.L., SORENSEN B., SKIBSTED L.H., BERTELSEN G. The antioxidative activity of summer savory (Satureja hortensis L.) and rosemary (Rosmarinus officinalis L.) in dressing stored exposed to light or in darkness. Food Chemistry, 63: 173-180, 1998. 
MARIUTTI L.R.B, BRAGAGNOLO N. A oxidação lipídica em carne de frango e o impacto da adição de sálvia (Salvia officinalis, L.) e de alho (Allium sativum, L.) como antioxidantes naturais. Revista do Instituto Adolfo Lutz (Impresso), 68(1), 1-11, 2009.

MELO A.E, MACIEL M.I.S, DE LIMA V.L.A.G, DO NASCIMENTO R.J. Capacidade antioxidante de frutas. Brazilian Journal of Pharmaceutical Sciences, 44(2), 2008.

MELO P.S, BERGAMASCHI K.B, TIVERON A.P, MASSARIOLI A.P, OLDONI T.L.C, ZANUS M.C, ALENCAR S.D. Composição fenólica e atividade antioxidante de resíduos agroindustriais. Ciência Rural, 41(6), 1088-1093, 2011.

MENSOR L.L, MENEZES F.S, LEITÃO G.G, REIS A.S, SANTOS T.C.D, COUBE C.S, LEITÃO S.G. Screening of Brazilian plant extracts for antioxidant activity by the use of DPPH free radical method. Phytotherapy research, 15(2), 127-130, 2001.

NEPA - NÚCLEO DE ESTUDOS E PESQUISAS EM ALIMENTAÇÃO. Tabela Brasileira de Composição de Alimentos (TACO). 4ed. Editora UNICAMP: Campinas, SP, p. 16-104, 2011

PACKER V.G, MELO P.S, BERGAMASCHI K.B, SELANI M.M, VILLANUEVA N D, DE ALENCAR, S.M, CONTRERAS-CASTILLO C.J. Chemical characterization, antioxidant activity and application of beetroot and guava residue extracts on the preservation of cooked chicken meat. Journal of Food Science and Technology, 1-8, 2015.

RACANICCI A.M.C, BENTE D, LEIF H.S. "Mate (Ilex paraguariensis) as a source of water extractable antioxidant for use in chicken meat." European Food Research and Technology 227.1: 255-260, 2008.

REGINATTO, M. F., RIBEIRO, A. M. L., PENZ JUNIOR, A. M., KESSLER, A. D. M., \& KRABBE, E. L. Suplementação de treonina em dietas de frangos de corte, variando a energia e as relações energia: proteína. Revista brasileira de ciência avícola. Brazilian journal of poultry science. Campinas, SP. Vol. 2, n. 3, p. 239-247, 2000.

RHEE KS. Enzymic and nonenzymic catalysis of lipid oxidation in muscle foods. Food Technol 42(6): 127-32, 1998. 
SELANI M.M, CONTRERAS-CASTILLO C.J, SHIRAHIGUE L.D, GALLO C.R, PLATAOVIEDO M, MONTES-VILLANUEVA N.D. Wine industry residues extracts as natural antioxidants in raw and cooked chicken meat during frozen storage. Meat science, $88(3)$, 397-403, 2011.

SINGLETON, VERNON ., RUDOLF ORTHOFER, ROSA M. LAMUELA-RAVENTOS. Analysis of total phenols and other oxidation substrates and antioxidants by means of folin-ciocalteu reagent." Methods in enzymology 299C: 152-178, 1999.

TAKAHASHI O, \& HIRAGA K. Dose-response study of hemorrhagic death by dietary butylated hydroxy toluene (BHT) in male rats. Toxicol. Appl. Pharmacol., New York, 43:399-406, 1978.

USDA.. U.S.A: Department of Agriculture: Agricultural Research Service, 2014. Disponível em: http://www.noticiasagricolas.com.br/noticias/usda/ .Acesso em: 11/09/2015

VIEIRA L.M, SOUSA M.S.B, MANCINI-FILHO J.O.R.G.E, LIMA A. Fenólicos totais e capacidade antioxidante in vitro de polpas de frutos tropicais. Revista Brasileira de Fruticultura, Jaboticabal, 33(3), 888-897, 2011.

VERMA A.K., RAJKUMAR V, BANERJEE R., BISWAS S, DAS A.K. Guava (Psidium guajava L.) powder as an antioxidant dietary fibre in sheep meat nuggets. AsianAustralasian journal of animal sciences, 26(6), 886, 2013.

WU, X.; BEECHER, G.R.; HOLDEN, J.M.; HAYTOWTTZ, D.B.; GEBHARDT, S.E.; PRIOR, R.L. Lipophilic and hydrophilic antioxidant capacities of common foods in the United States. J. Agric. Food Chem., Washington, v.52, n.12, p.4026-4037, 2004. 


\section{CAPÍtULO 4}

\section{CONSIDERAÇÕES FINAIS}

O uso da goiaba na produção de sucos e doces, é muito utilizado no país, e os resíduos dessa produção geralmente não são aproveitados. Sabendo-se do potencial antioxidante dos resíduos dessa fruta, junto a busca do uso de substancias naturais em substituição as sintéticas, esse estudo teve como objetivo avaliar a capacidade antioxidante do extrato de goiaba na conservação de carne de frango em congelamento e refrigeração.

O extrato mostrou ser um excelente antioxidante natural, em alguns momentos sendo melhor do que o antioxidante sintético BHT, sendo assim um possível substituto aos antioxidantes sintéticos utilizados em produtos cárneos.

Estudos sensoriais não foram realizados neste trabalho, nem encontrados em literatura para o uso de goiaba em produtos cárneos, assim é necessário uma complementação desse estudo, para verificar a real possibilidade do uso de extrato de goiaba em produtos comerciais. 